\title{
Structural Analyses of the Storage Container for Heavy Element Facility, Building-251
}

\author{
D.S. $\mathrm{Ng}$
}

January 1, 1999

U.S. Department of Energy

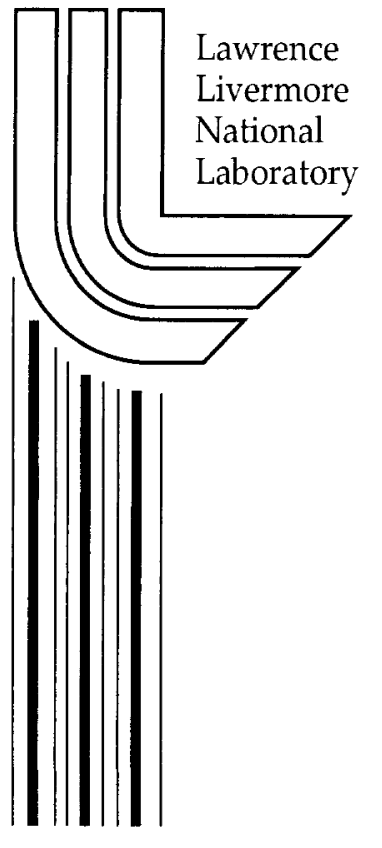




\section{DISCLAIMER}

This document was prepared as an account of work sponsored by an agency of the United States Government. Neither the United States Government nor the University of California nor any of their employees, makes any warranty, express or implied, or assumes any legal liability or responsibility for the accuracy, completeness, or usefulness of any information, apparatus, product, or process disclosed, or represents that its use would not infringe privately owned rights. Reference herein to any specific commercial product, process, or service by trade name, trademark, manufacturer, or otherwise, does not necessarily constitute or imply its endorsement, recommendation, or favoring by the United States Government or the University of California. The views and opinions of authors expressed herein do not necessarily state or reflect those of the United States Government or the University of California, and shall not be used for advertising or product endorsement purposes.

This work was performed under the auspices of the U. S. Department of Energy by the University of California, Lawrence Livermore National Laboratory under Contract No. W-7405-Eng-48.

This report has been reproduced directly from the best available copy.

Available electronically at http://www.doe.gov/bridge

Available for a processing fee to U.S. Department of Energy

and its contractors in paper from

U.S. Department of Energy

Office of Scientific and Technical Information

P.O. Box 62

Oak Ridge, TN 37831-0062

Telephone: (865) 576-8401

Facsimile: (865) 576-5728

E-mail: reports@adonis.osti.gov

Available for the sale to the public from

U.S. Department of Commerce

National Technical Information Service

5285 Port Royal Road

Springfield, VA 22161

Telephone: (800) 553-6847

Facsimile: (703) 605-6900

E-mail: orders@ntis.fedworld.gov

Online ordering: http://www.ntis.gov/ordering.htm

\section{OR}

Lawrence Livermore National Laboratory

Technical Information Department's Digital Library

http://www.Ilnl.gov/tid/Library.html 


\section{Structural Analyses of the Storage Container}

for

Heavy Element Facility, Building-251

Dorothy S. Ng

Structural Mechanics Group

New Technologies Engineering Division

Lawrence Livermore National Laboratory

January 1999 


\section{Table of contents}

Abstract... - - -

$1.0 \quad$ Introduction

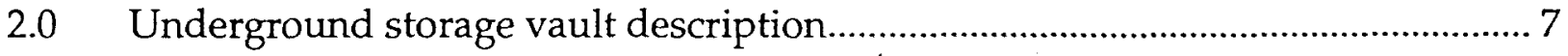

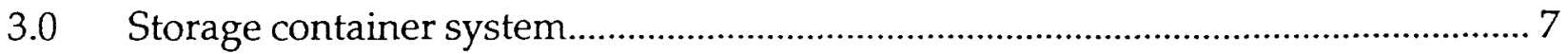

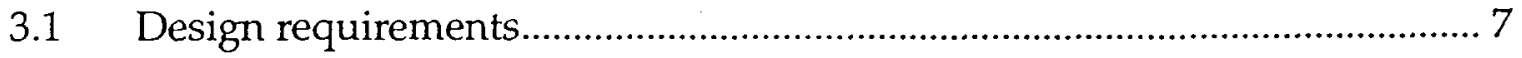

3.2 Description of the storage container............................................................ 8

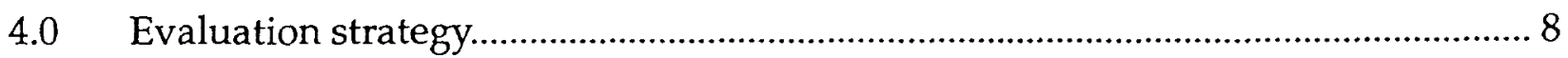

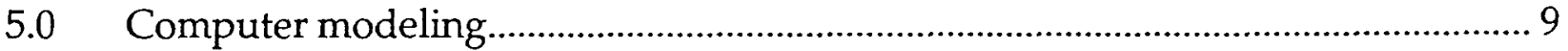

$5.1 \quad$ Model description ..................................................................................... 10

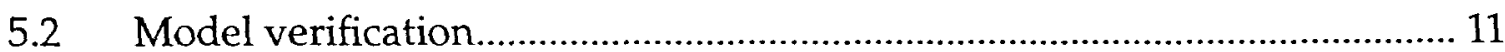

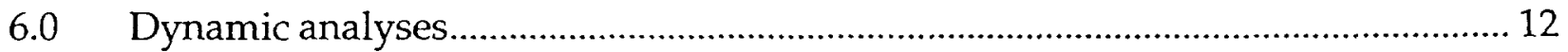

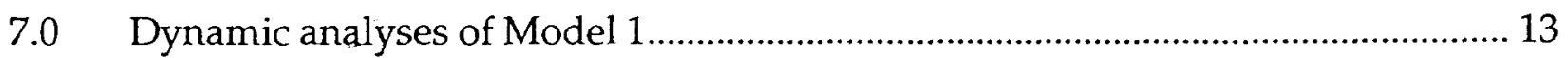

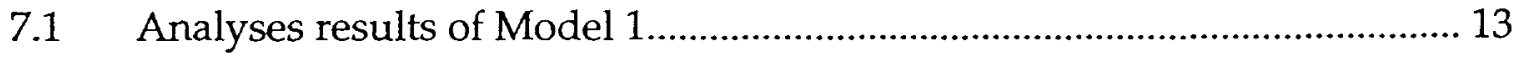

7.2 Structural evaluation of Model 1............................................................... 14

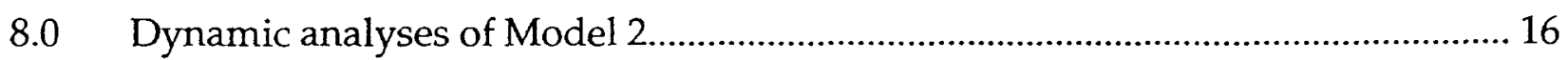

8.1 Analyses results of Model 2 ………………………................................... 16

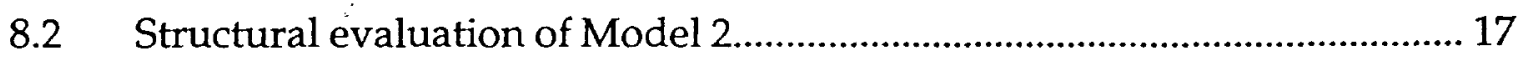

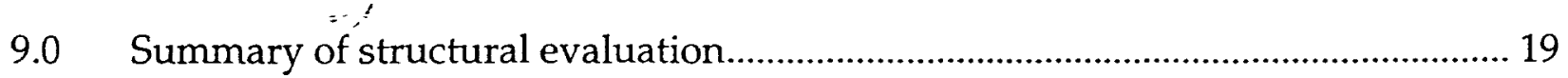

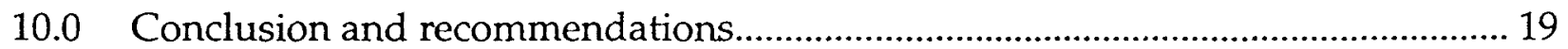

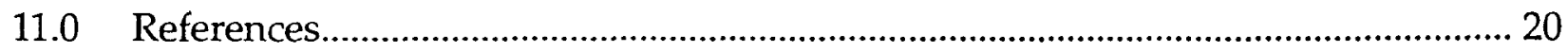




\section{Table of contents}

Figure 1.1 The under ground storage rack (not to scale)............................................... 21

Figure $3.1 \quad$ A detailed drawing of the storage container............................................. 22

Figure 5.1 Model 1 is configured for maximum mass impact on the flanges.

Figure 5.2 Model 2 is configured to capture the impact from the capsule and juice can travelling inside the container.

Figure 5.3 A close-up view of the deformed O-ring assembly after a $51.76^{\circ}$ drop 24

Figure 5.4 A close-up view of the lid/flange separation after a $51.76^{\circ}$ drop. 24

Figure 7.1 A composite plot of the deformed models and effective stress distribution of three drop orientations: (a) $20^{\circ}$, (b) $30^{\circ}$, and (c) $51.76^{\circ} \ldots \ldots . .25$

Figure 7.2 A composite plot of the effective stress time histories of three drop orientations: (a) $20^{\circ}$, (b) $30^{\circ}$, and (c) $51.76^{\circ}$ 26

Figure 7.3 A composite plot of the longitudinal displacement time histories of three drop orientations: (a) $20^{\circ}$, (b) $30^{\circ}$, and (c) $51.76^{\circ}$. 27

Figure 7.4 The projected drop angle for maximum deformation. 28

Figure 7.5 A close-up view of the deformed O-ring assembly after the $37^{\circ}$, $17.5 \mathrm{ft}$ drop.

Figure 7.6 A close-up view of the lid/flange separation after the $37^{\circ}, 17.5 \mathrm{ft}$ drop.

Figure 7.7 The longitudinal displacement time histories along the symmetry plane from the $37^{\circ}, 17.5 \mathrm{ft}$ drop at (a) flange, (b) bolt hole, and

(c) groove 30

Figure 7.8 The longitudinal displacement time histories along the symmetry plane from the $37^{\circ}, 17.5 \mathrm{ft}$ drop at (a) flange, (b) bolt hole, and (c) groove. 
Figure 7.9 A schematic of the deformed O-ring assembly.

Figure 8.1 The deformed shape and position of Model 2 at $20 \mathrm{~ms}$ after impact at the $37^{\circ}$ orientation and $17.5 \mathrm{ft}$ drop

Figure 8.2 A composite plot of the deformed model and longitudinal displacement distribution of: (a) $62.64^{\circ}$, (b) $70^{\circ}$, and (c) $90^{\circ}$.

Figure 8.3 A composite plot of the effective stress time histories of three drop orientations: (a) $62.64^{\circ}$, (b) $70^{\circ}$, and (c) $90^{\circ}$

Figure 8.4 A composite plot of the longitudinal displacement time histories of three drop orientations: (a) $62.64^{\circ}$, (b) $70^{\circ}$, and (c) $90^{\circ}$

Figure 8.5 The projected drop angle for maximum deformation 36

Figure 8.6 A close-up view of the deformed O-ring assembly after the $70^{\circ}$, $17.5 \mathrm{ft}$ drop.

Figure 8.7 A close-up view of the lid/flange separation after the $70^{\circ}, 17.5 \mathrm{ft}$ drop

Figure 8.8 The longitudinal displacement time histories on the symmetry plane from the $70^{\circ}, 17.5 \mathrm{ft}$ drop at (a) flange, (b) bolt hole, and (c) groove. 38

Figure 8.9 The longitudinal displacement time histories on the symmetry plane from the $70^{\circ}, 17.5 \mathrm{ft}$ drop at (a) flange, (b) bolt hole, and (c) groove. 39

Figure 8.10 Two groups of shell elements in the juice can were evaluated 40

Figure 8.11 The maximum effective stress time histories in the juice can....................... 40

Figure 8.12 The effective plastic strain time histories in the juice can........................... 41 


\begin{abstract}
The Heavy Element Facility, Building 251, contains a series of underground storage vaults which are used for long term storage of nuclear materials. A storage rack with shelves is suspended from the top of each storage vault. The stainless steel containers enclosing the nuclear materials are stored on the shelves.

A Hazard \& Accident assessment analyzed the vulnerability of this storage system to assaults resulting from natural phenomena and accidents within the building. The assessment considered all racks and their containers to be stored underground and secured in their static, long-term configuration.

Moving beyond the static, long-term hazard assessment, the structural analyses were performed to evaluate the storage container against a rare, short duration event. An accidental free drop of a container may occur in a combination of two events: a rare, short-duration earthquake concurrent with an operation of raising the storage rack to a maximum height that the crane is capable of. This hypothetical free drop may occur only to the container in the uppermost shelf of the storage rack.

The analyses were the structural evaluation of the storage container to determine the material containment integrity of the storage container after the accident. The evaluation was performed simulating a free drop from the storage rack, with a maximum load in the container, striking an unyielding surface in the worst orientation.

The analyses revealed that, in the very unlikely event of a container drop, the integrity of the hermetic seal of the storage container could be compromised due to plastic deformation of the lid and mating flange. Simple engineering and administrative controls can prevent that from occurring.
\end{abstract}




\subsection{Introduction}

The Heavy Element Facility, Building 251 (B-251), is a Lawrence Livermore National Laboratory (LLNL) legacy facility, managed on behalf of the institution by the Physics \& Space Technology (P\&ST) directorate. The facility contains 12 underground storage vaults (wells), used for long term storage of nuclear materials. A storage rack with 9 shelves is suspended in each well. The stainless steel containers enclosing the nuclear materials are stored on the shelves.

The facility is designated to be a Category 3 Nuclear Facility in accordance with DOE Order 5480.23 (Ref. 1). A Safety Analysis Report (SAR) (Ref. 2) has been approved for B-251 in December 1994. The historical mission of B-251 was to support tests at the Nevada Test Site (NTS). Since the demise of nuclear testing, no other programmatic need for the facility has been identified; consequently, the facility has been in a standby mode.

A Hazard \& Accident (H\&A) assessment (Ref. 3) analyzed the vulnerability of this storage system to assaults resulting from natural phenomena and accidents within the facility. The H\&A analysis followed the guidance of DOE-STD-1027-92 (Ref. 4). The analysis considered all racks and their containers to be stored underground and secured in their static, long-term configuration. The analysis did not include, in its scope, the extraction of some containers from their storage position for future use or offsite transportation.

Moving beyond the static, long-term hazard assessment the structural analyses were performed to evaluate the storage container against a rare, short duration event. Based on the configuration of the container and storage operation, an accidental free drop of a container may occur in a combination of two events: a rare, short-duration earthquake concurrent with an operation of raising the storage rack to a maximum height that the crane is capable of. The hypothetical free drop may occur only to the container in the uppermost shelf of the storage rack because the lower eight shelves do not have sufficient space for the container to tip and fall off.

The structural analyses simulated the dynamic impact on the storage container from falling off the storage rack and calculated the container's structural responses induced by the impact. The purpose of the dynamic analyses was to demonstrate that the container would maintain its material containment capability after the accident. The stored material would be contained if the storage container remains air tight after a drop impact. 


\subsection{Underground storage vault description}

A total of 12 underground storage vaults are located in the Room 1320 of B-251. An 11-fttall storage rack with 9 shelves is suspended in each well as Fig. 1.1 shows. The vertical space between the shelves is $12.5 \mathrm{in}$. except for the top shelf, which is slightly over 14 in. Each shelf has a lip around its edge which prevents the container from sliding off the shelf. Storage containers are 11.5-in. tall and 6 in. in diameter. Because their diagonal dimension is 13 in., which is larger than the vertical space of the lower shelves (12.5 in.), there is not enough room for a container to tip and fall if the rack should sway from sideto-side. In fact, the container must be held level to be placed on the shelf.

The container sits inside the uppermost shelf with a clearance of $2.5 \mathrm{in}$. The clearance provides enough room for the storage container to tip and fall off the shelf if the angle of sway is sufficiently large. The lip of the shelf is not tall enough to prevent the fall.

The seismic analysis in the SAR indicated that the roof of B-251 could be severely damaged when the building is subjected to a ground motion of $0.8 \mathrm{~g}$. The damaged roof could cause the crane and the storage rack suspended from it to sway vigorously; therefore, the above fall scenario should be evaluated for material containment integrity of the storage container.

\subsection{Storage container system}

\subsection{Design requirements}

The storage container was designed in December 1971. The operational design specification requires that the storage container must remain air tight when subjected to an external air pressure of 45 psig while immersed in water.

The 10CFR71 (Ref. 5) provides specific drop requirements for the design of a shipping container for fissile material but no drop requirement for a storage container. According to 10CFR71, a shipping container for fissile material should provide material containment under normal conditions and hypothetical accident conditions. Although the storage container is not used for shipping, the shipping container provision is used here for reference and for conservatism.

One of the normal operating conditions is free drop of the shipping container striking a flat, essentially unyielding, horizontal surface in a position for which maximum damage is expected. The drop distance is determined by the weight of the loaded shipping container. When the shipping container weighs less than $11,000-1 \mathrm{~b}$, the required drop distance is $4 \mathrm{ft}$. The B-251 storage container weighs under $20 \mathrm{lb}$; therefore, a drop distance of $4 \mathrm{ft}$ is sufficient. 
10 CFR71 also requires a shipping container to maintain material containment after a hypothetical accident of a drop at a height of $30 \mathrm{ft}$. The hypothetical accident defined for the storage container is a free drop from the top shelf onto the floor. The maximum lifting distance of the building crane is $18.5 \mathrm{ft}$ from the floor. The distance between the hoisting fixture to the top shelf is about $1 \mathrm{ft}$; therefore, the maximum accidental drop distance is $17.5 \mathrm{ft}$ which supersedes the 4 - $\mathrm{ft}$ requirement.

\subsection{Description of the storage container}

The storage container system consists of two nested components: a juice can contained in a stainless steel storage container. There are several types of encapsulated material stored in the juice can: the higher-radioactivity materials are tracers in pressed-pellet form, while others are in powder form. The capsules vary from glass bottles to lead canisters depending on the nature of the heavy element. The active heavy-element is shielded in a lead capsule. The largest lead capsule is 2-3/4 in. in diameter, 5-1/2-in. long, 3/8 in. in wall thickness and weighs $7 \mathrm{lb}$.

The juice can is made of a 0.0142 -in-thick tin sheet rolled into a tube. The tube is 4.18 in. in diameter, 7 -in. long and weighs $0.5 \mathrm{lb}$. The juice can is crimped at the bottom with a metal plate of the same thickness as the cylinder. The lid of the juice can is also crimped on after the loaded capsule is placed in the can. The capsule is free to move and rotate inside the juice can because the juice can is larger than the capsule.

The outside storage container, which weighs $9.15 \mathrm{lb}$, is made of a 5.0-in.-diameter, 11.12in.-tall, schedule 40 stainless steel tube. Fig. 3.1 is a detailed drawing of the container. The base of the cylinder is welded to a 0.25 -in.-thick base plate. The thickness of the base plate outside the cylinder (flange) is reduced to $0.125 \mathrm{in}$.

The top of the cylinder is welded to a 0.344 -in.-thick flange and is covered with a 0.24 -in.thick lid. The lid is bolted to the flange with six 0.25 -in.-diameter bolts. The stainless steel container is designed to be air tight. The air seal is provided by a 0.25 -in.-diameter, neoprene O-ring situated in the rectangular groove in the container flange and compressed by the lid. The designed compression of the O-ring assembly is equivalent to $50 \mathrm{lb}$ per linear inch ( $\mathrm{lb} /$ in.) of the O-ring.

\subsection{Evaluation strategy}

Based on the configuration of the storage container and storage operation, a hypothetical accident was identified to be a free drop of the storage container from the storage rack during operation. The structural evaluation focuses on the compliance of the material containment requirement. The material containment integrity of the storage containers was investigated based on the following assumptions: 
- Maximum load in the container

- Striking an unyielding surface

- At the most damaging orientation.

The material containment in a storage container may be insured by any of the three components: the capsule, juice can, or container. Most of the higher-radioactivity items are stored in lead capsules which are the primary containment for the material. The lead capsule is closed with a 3/8-in.-tall step joint cover. The loaded capsule is taped around the step joint then wrapped in aluminum foil. It is unlikely that the step joint will separate accidentally, allowing the material to escape.

The loaded juice can is crimped at the base and top. Because the tin sheet is flexible it may be deformed by the capsule impact. As stated in the H\&A analysis report, the juice can is not required to remain leak-tight. However, the juice can is evaluated here for plastic strain. It will be considered to maintain its material containment if it experiences a plastic strain less than $2 \%$.

The storage container, which provides the secondary containment, is designed to be air tight. In comparison with the weldment in the container cylinder, the container O-ring assembly is more vulnerable to impact damage. The O-ring was designed for a compression of $50 \mathrm{lb} /$ in. when the flanges are bolted to full contact. In case of an accidental drop, the lid and the flange in the O-ring assembly could deform (buckle) or separated from each other, releasing the compression on the O-ring and losing the air seal as a result. Therefore, the structural evaluation focuses on the relative deformation of the lid and the flange in the O-ring assembly.

In the case that the air seal remains functional after an impact, the calculated dose consequence quantities in the H\&A analysis will be unchanged, which are the orders of magnitude below the Category- 2 and Category- 3 threshold dose criteria given in the DOE-STD-1027-92. If the lid and the flanges are severely separated by the impact and lose the air seal in the storage container, the secondary containment is considered to be breached.

\subsection{Computer modeling}

The structural evaluation of the storage container was performed by the finite element analyses using the DYNA3D (Ref. 6), which is a nonlinear, explicit, three-dimension (3D) finite element code. It calculates transient dynamic response and captures the stress wave propagation through the materials of the model. Using small time steps, it calculates an explicit solution at each step, producing displacement, velocity, and acceleration time histories for each node point as well as the stress and strain time histories for each element. The finite element model, representing the storage container, 
was generated using TrueGrid (Ref. 7), which produces a ready-to-execute DYNA3D input file.

\subsection{Model description}

Because the storage container is symmetric about the longitudinal planes, taking advantage of the symmetry, only one-half of the container is needed to model the entire container. Because the lid is more vulnerable to damage at midpoint between bolts than at the bolts, the plane of symmetry was placed at the midpoint between two adjacent bolts. Proper boundary conditions were imposed on the node points on the plane of symmetry to simulate the missing half of the container.

The geometric configuration of the modēl was generated to represent the dimensions of the structure, and the material properties were input to represent the proper structural stiffness. An impact velocity calculated from the drop distance was input as an initial nodal velocity. A stonewall with fixed displacement was modeled to represent the impact target.

To account for frictional interaction of the adjacent components in the container, coefficient of frictions (COF) were defined on the component surfaces at the container/ juice can, juice can/capsule, flange/lid, and O-ring/flange/lid interfaces. This option allows the adjacent components to slide on or impact from each other. The COFs were obtained from the literature and past experience.

In addition to the impact distance and the angle to the impact surface, the mass of the container components have strong effect on the structural response. Two assumptions on the structural masses were made resulting in the generation of Models 1 and 2 . In fact the assumption for Model 2 was based on the evaluation of the analysis results from Model 1.

Model 1 is a simplified case. In this model the capsule was not included but its weight was distributed as part of the juice can cylinder. The juice can is placed adjacent to the top of the container putting the concentrated capsule mass at the top flanges. In this configuration, the juice can impacts the rigid surface at about the same time as the container's top flange. This model produces direct impact to the O-ring assembly with the maximum mass; but, ignores the dynamic impact of the capsule and the juice can induced by travelling inside the container. Model 1, shown in Fig. 5.1, is oriented in the top-drop orientation. The center-of-gravity (c.g.) of Model 1 is aligned vertically with its top corner at an angle of $51.76^{\circ}$ and the model is composed of 6,193 node points and the following two types of elements:

- 3,326 solid elements for the cap, flange, bolts, and O-ring.

- 976 shell elements for the container cylinder, base plate, and juice can. 
Fig. 5.2 shows Model 2 oriented in a top-drop orientation and in the normal storage configuration with the capsule and juice can resting at the base of the container. During the fall, the container rotates with its top end moving towards the rigid floor, whereas, the capsule and juice can travel from the base to the top of the container. Although Model 2 requires intensive computer time to simulate the travel of the internal components, it captures the impact from the travelling capsule and juice can which produce deformation larger than that in Model 1. The c.g. of Model 2 is aligned with its top corner at an angle of $62.64^{\circ}$ and the model is composed of 6,731 node points and the following two types of elements:

- 3,637 solid elements for the cap, flange, bolts, O-ring, and capsule.

- 976 shell elements for the container cylinder, base plate, and juice can.

\subsection{Model verification}

The finite element model was verified qualitatively with experimental results. Previous to these analyses two simple drop tests were performed on the empty storage container to evaluate the survivability of the container. The same container was dropped twice from the roof of B-251 onto the ground at a distance of $29 \mathrm{ft}$. The first drop was planned for bottom impact, while the second drop was planned for top impact. Unfortunately, both drop tests were not controlled or monitored by instrumentation.

The non-symmetrically buckled cylinder resulted from the tests indicates that the container did not impact flat on the bottom nor the top, but at some unknown angle to the longitudinal axis of the container. In addition, because the tested container was not loaded with a capsule and a juice can, the deformation can only be used for qualitative comparison. Fortunately, the impact point of the top drop test was close to the midpoint between two bolts, which is the selected point of impact in the computer simulation.

Multiple drop orientations were tested for impact angles of $20^{\circ}, 30^{\circ}$, and $51.76^{\circ}$ with respect to the longitudinal axis of the container. The drop distance was held at $29 \mathrm{ft}$, which is the same-as that in the drop tests. The deformed shape of the container produced from the top-drop at the $51.76^{\circ}$ angle with respect to the longitudinal axis appears to be the best match to the top-drop test. Figs. 5.3 and 5.4 are close-up views of the deformed shape of Model 1. Fig. 5.3 shows the plastic deformation of the lid/flange on the symmetry plane. Fig. 5.4 is shows a small separation at the outer surface of the flanges which is similar to that on the tested container. The color bars in these figures indicate the level of effective stresses.

\subsection{Dynamic analyses}

The choice of drop orientation was dictated by the vulnerability of the O-ring assembly 
rather than by the integrity of the container contents. The following typical drop orientations were investigated to identify the controlling orientation which causes the most severe damage to the container:

- Bottom drop

- Side drop

- Angle drop on the bottom allowing the top to snap down

- Top drop

- Center of gravity (c.g.) over top corner drop

- Angle drop over top corner.

The bottom drop and side drop orientations do not apply a bending moment to the lid and flange where the O-ring assembly is located. Because they do not threaten the vulnerability of the $\mathrm{O}$-ring assembly, they were not simulated.

Allowing the container to drop on its bottom flange at an angle would cause the container to bounce up and then to snap down on its top end. This drop orientation would induce more stresses on the internal components of the payload, in comparison with an angle drop over top corner. Because there are no fragile internal components in the container, this drop configuration was not analyzed.

When the container is dropped on its top, the lid will deflect and separated from the flange due to the impact from the capsule and juice can. When the container is dropped with its c.g. aligned with the top corner, it will bounce upward because there is no rotation inducing eccentricity. The impact induces a bending moment on the lid which buckles as a result. When the container is dropped at an angle other than that which aligns the c.g. with vertical, it will bounce with rotation inducing eccentricity; thus, imposes bending moment in the lid and flange. The dynamic responses could be larger than those from the c.g. over top corner drop.

To identify the worst case, many drop angles were selected for each model: $20^{\circ}, 30^{\circ}$, and $51.76^{\circ}$ for Model 1 and $37^{\circ}, 51.76^{\circ}, 62.64^{\circ}, 70^{\circ}$, and $90^{\circ}$ for Model 2. A $90^{\circ}$ refers to a top drop. The drop distance was kept at $29 \mathrm{ft}$ for Model 1 and $17.5 \mathrm{ft}$ for Model 2. The orientation of the stonewall with fixed displacement was positioned to show the angle of contact for each case. The geometric orientation of the container system remained unchanged.

At the point of impact, the lid and flange will deform. The relative deformation in the longitudinal direction of the lid and flange is used as a measure of damage. From the response time history, the maximum deformation occurs within the first $5 \mathrm{~ms}$ after impact; therefore, the termination time for computer simulation was set to be $5 \mathrm{~ms}$. The iteration time step size is controlled by the size and mass of the finite elements in the model. The smallest and lightest elements are those representing the bolts, which reduce 
the step size to $0.1 \mu \mathrm{s}$. One-and-a-half hours of CPU time is required to complete a 5-ms analysis.

Although the maximum responses occur at $5 \mathrm{~ms}$ after impact, the energy is not totally dissipated at that time. It is necessary to increase the simulation time to further dissipate the energy until the separation in the O-ring assembly converges (plastic, not elastic). A 20-ms analysis was performed in two steps: an initial 5-ms analysis and a restart 15-ms analysis. In some cases, the analysis time was extended to over $20 \mathrm{~ms}$ to ensure that the separation converged.

\subsection{Dynamic analyses of Model 1}

The results from the $20^{\circ}, 30^{\circ}$, and $51.76^{\circ}$ drops indicated that the maximum relative separation in the flanges would occur between $30^{\circ}$ and $51.76^{\circ}$. The drop distance was changed to a realistic value of $17.5 \mathrm{ft}$ to evaluate material containment.

\subsection{Analyses results of Model 1}

Fig. 7.1 is a composite plot of three deformed container models at three drop orientations, $20^{\circ}, 30^{\circ}$, and $51.76^{\circ}$. The maximum effective stress occurs at the point of contact (the tip of the cap). The 'elephant-foot' buckling in the cylinder is visible in the $30^{\circ}$ and $51.76^{\circ}$ drops.

Fig. 7.2 is a composite plot of effective stress time histories resulting from three drop orientations: $20^{\circ}, 30^{\circ}$, and $51.76^{\circ}$. In the legend, the first four solid elements are in the flange, while the following four are in the container lid. At the low impact angle $\left(20^{\circ}\right)$, the tip of the flange experiences high stress. The arrival time for the juice can is slower than at high impact angles $\left(30^{\circ}\right.$ and $\left.51.76^{\circ}\right)$.

The multiple peaks of effective stress indicate that the lid contacts the stonewall first, followed by the impact of the juice can first at the top of the container, then at the container cylinder. Note that the maximum effective stress occurs in different solid elements at different times which indicates that the capsule contact time could be important to the resulting responses. Thus, the dynamic impact from the travelling capsule/juice must be included in the analysis.

Fig. 7.3 is a composite plot of longitudinal displacement time histories resulting from three drop orientations. Because the global displacements in each drop orientation are different in magnitude, the scale for each plot is different. At low-angle impact, the high displacement is caused by the bouncing and rotating of the container, which is induced by the eccentricity of the c.g. As the impact angle increases to $51.76^{\circ}$, the container 
bounces along the vertical line that passes through the c.g. of the container assembly and no rotation is encountered. The resulting displacements are lower.

For $20^{\circ}, 30^{\circ}$, and $51.76^{\circ}$ drops, the separations (differential longitudinal displacement) between the lid and the flange were calculated from the deformation time histories to be about $0.035,0.050$, and 0.044 in., respectively. The separations were plotted as a function of impact angle, as Fig. 7.4 shows.

A curve was fitted over these three values in a scaled plot. The peak of the curve appeared to be approximately $37^{\circ}$; therefore, the maximum separation in the O-ring assembly would occur when the impact angle was near $37^{\circ}$. A simulation was performed at a $37^{\circ}$ drop angle with a drop distance of $17.5 \mathrm{ft}$ to obtain the worst case flange separation. The simulation time was set to $20 \mathrm{~ms}$.

\subsection{Structural evaluation of Model 1}

The focus of the structural evaluation is on the material containment integrity of the storage container. Significant separations between the lid and flange are visible at the plane of symmetry (Fig. 5.3) and at the cross section $60^{\circ}$ angle with respect to the plane of symmetry (Fig. 6.4). Consequently, separation at these two cross-sections were evaluated and summarized in Tables 1 and 2.

Close-up views of deformed shapes are depicted in Figs. 7.5 and 7.6. On the symmetry plane, the separation is larger at the outer edge of the flange and decreases as it approaches the $\mathrm{O}$-ring groove. The separation at the impact point does not appear to be a gap. This occurs because of the lid bending which pushes the lid against the flange, as shown in Fig. 7.5.

The longitudinal displacement time histories at three locations on the symmetry plane and along the $60^{\circ}$ cross section from the $17.5 \mathrm{ft}, 37^{\circ}$ drop are shown in Figs. 7.7 and 7.8, respectively. The separation appears to be larger at the O-ring groove than at the outer edge of the flange. The calculated deformation time histories show a separation at the outer edge of the groove to be a maximum of 0.025 in., which is reduced by half $(0.012$ in.) as the simulation time approaches $20 \mathrm{~ms}$. These values are used to evaluate of the integrity of the air seal in the O-ring assembly. 
Table 1: The longitudinal displacements are investigated at these node points on the symmetry plane

\begin{tabular}{|c|c|c|c|}
\hline \multirow{2}{*}{ Component } & \multicolumn{3}{|c|}{ Outer edge } \\
\cline { 2 - 4 } & Flange & Bolt hole & Groove \\
\hline \hline Cap & No. 3003 & No. 2415 & No. 2063 \\
\hline Flange & No. 4503 & No. 4167 & No. 3623 \\
\hline
\end{tabular}

Table 2: The longitudinal displacements are investigated at these node points along the cross section $60^{\circ}$ with respect to the point of impact.

\begin{tabular}{|c|c|c|c|}
\hline \multirow{2}{*}{ Component } & \multicolumn{3}{|c|}{ Outer edge } \\
\cline { 2 - 4 } & Flange & Bolt hole & Groove \\
\hline \hline Cap & No. 3209 & No. 2614 & No. 2156 \\
\hline Flange & No. 4623 & No. 4283 & No. 3807 \\
\hline
\end{tabular}

Fig. 7.9 shows the depth of the groove is 0.152 in., with a tolerance of 0.0 to +0.01 . The depth of the groove could be as large as $0.162 \mathrm{in}$. The diameter of the O-ring is $0.21 \mathrm{in}$., with tolerance from +0.005 to -0.005 ; thus, it could be 0.0215 to 0.0205 in. By design, the compression on the selected $\mathrm{O}$-ring is equivalent to $50 \mathrm{lb}$ per linear inch of the $\mathrm{O}$-ring.

The compression set was calculated using the equations provided in the O-ring manufacturer's handbook (Ref. 8). From the compression set, the resulting compression can be calculated, as well as the equivalent compression load remaining in the O-ring. Table 3 tabulates the calculated compression set, percent of compression, and compression load remained in the $\sigma$-ring.

The remaining compression load in the O-ring after impact was calculated at various combinations: nominal dimensions, maximum tolerance, and minimum tolerance. The remaining compression from the least and most conservative approaches are 30 and 10.5 $\mathrm{lb} /$ in., respectively, reduced to $60 \%$ and $20 \%$. Such pressure reduction does not provide a comfortable margin. From the above analyses conclusion was drawn to investigate the impact on the container from the travelling capsule and juice can. 
Table 3: The calculated compression loads in the $\mathrm{O}$-ring after drop impact.

\begin{tabular}{|c|c|c|c|c|c|}
\hline $\begin{array}{l}\text { O-ring relative } \\
\text { deformation } \\
\text { (in.) }\end{array}$ & $\begin{array}{l}\text { Groove } \\
\text { depth } \\
\text { (in.) }\end{array}$ & $\begin{array}{l}\text { O-ring } \\
\text { diameter } \\
\text { (in.) }\end{array}$ & $\begin{array}{l}\text { Comp. } \\
\text { set } \\
(\%)\end{array}$ & $\begin{array}{l}\text { Remaining } \\
\% \text { of compression } \\
(\%)\end{array}$ & $\begin{array}{l}\text { Remaining } \\
\text { comp. load } \\
\text { (lb/in) }\end{array}$ \\
\hline 0.012 & 0.152 & 0.21 & 79.3 & 21.9 & 30.0 \\
\hline 0.025 & 0.152 & 0.21 & 56.9 & 15.7 & 14.5 \\
\hline 0.025 & 0.162 & 0.21 & 40.0 & 11.0 & 11.0 \\
\hline 0.025 & 0.162 & 0.205 & 34.0 & 9.4 & 10.5 \\
\hline
\end{tabular}

\subsection{Dynamic analyses of Model 2}

Model 2 was created based on the evaluation of Model 1. The concern was that the dynamic impact of the capsule travelling 5.5 in. in the container might induce more pressure reduction on the O-ring than the lumped mass assumption. Model 2 was tested at the drop orientation of $37^{\circ}$ from $17.5 \mathrm{ft}$ to examine the dynamic effect from the travelling capsule. The capsule dropped on the side of the container which in turn caused the container to fall on its side. Fig. 8.1 shows the position of the container at 27 $\mathrm{ms}$ after impact. Note that the capsule did not reach the lid. Consequently, to identify the worst drop orientation, the angle was iteratively increased to $51.76^{\circ}, 62.64^{\circ}, 70^{\circ}$ and bounded by the top drop orientation $\left(90^{\circ}\right)$. The results from the $51.76^{\circ}$ drop were similar to those obtained from the $37^{\circ} \mathrm{drop}$. The results from the $62.64^{\circ}, 70^{\circ}$, and $90^{\circ}$ drops are presented in the following subsections.

\subsection{Analyses results of Model 2}

Fig. 8.2 is a composite plot of three deformed container models at three drop orientations: $62: 64^{\circ}, 70^{\circ}$, and $90^{\circ}$. All three plots correspond to the time when the capsule impacted the lid of the container. In the $62.64^{\circ}$ and $70^{\circ}$ drops, the capsule and juice can bounced and slid along the side of the container cylinder then struck the center of the lid. Elephant-foot buckling in the container cylinder is visible in these two drops.

In the $90^{\circ}$ drop, the container bounced vertically along its longitudinal axis and struck the falling juice can and capsule at $12 \mathrm{~ms}$ after impact. The lid of the container was deflected by the capsule impact. There is no elephant-foot buckling in the container cylinder.

Fig. 8.3 is a composite plot of effective stress time histories resulting from three drop 
orientations: $62.64^{\circ}, 70^{\circ}$, and $90^{\circ}$, respectively. In the legend, the location of the finite elements are the same as those in Model 1. The spikes in the time histories induced by the capsule impact correspond to the time shown in the deformed shape plots, 15.8, 16.3, and $12.5 \mathrm{~ms}$ for the $62.64^{\circ}, 70^{\circ}$, and $90^{\circ}$ drops, respectively. The later two cases had more than one capsule contact.

Fig. 8.4 is a composite plot of longitudinal displacement resulting from three drop orientations. Note that the overall displacements in each drop orientation are different in magnitude, thus the scale in each plot is different.

To ensure that the energy in the container system was fully dissipated, the termination time was extended to $30 \mathrm{~ms}$ for the $62.64^{\circ}$ and $90^{\circ}$ drops and to $35 \mathrm{~ms}$ for the $70^{\circ}$ drop. The separations are quite uniform in the last $5 \mathrm{~ms}$. Because no rotation of the can was encountered in both the $62.64^{\circ}$ drop (c.g. over top corner drop) and $90^{\circ}$ drop (top drop) orientations, they produced O-assembly separation at a lower stress level than that from the $70^{\circ}$ drop.

The separations between the lid and flange were calculated to be $0.019,0.041$, and 0.027 inch for the $62.64^{\circ}, 70^{\circ}$, and $90^{\circ}$ drops, respectively. The separations were plotted in Fig. 8.5 as a function of impact angle. A curve was fitted over these three values in the scaled plot. The peak of the curve appeared near $80^{\circ}$ at which the maximum separation in the $\mathrm{O}$-ring assembly would occur. The projected separation from the $80^{\circ}$ drop is 0.044 in. which was used for material containment evaluation.

\subsection{Structural evaluation of Model 2}

In the $70^{\circ}$ drop, the corner of the capsule in Model 2 struck the center of the lid at $16 \mathrm{~ms}$ after impact. Figs. 8.6 and 8.7 show the close-ups of the deformed shapes of Model 2 taken at $16 \mathrm{~ms}$ after impact. Fig. 8.6 shows that the center of the lid is deflected by the impact from the capsule, while the outer edge of the lid is fixed to the flange by the bolts. At the impact point, the lid and flange are being compressed to two parallel plates. Fig.

8.7 shows the flange separation at $60^{\circ}$ with respect to the point of impact.

Fig. 8.8 is a composite plot of longitudinal displacement at three locations (flange, bolt hole, and groove) on the O-ring assembly at impact. The separation between the lid and flange is quite uniform across the flange, which confirms that the lid and flange remained parallel to each other.

Fig. 8.9 is a composite plot of the longitudinal displacement time histories at the three locations along the cross section at $60^{\circ}$ from the point of impact. The maximum separation at the outer edge of the groove is $0.041 \mathrm{in}$. at $35 \mathrm{~ms}$ after impact. The 
separations at the $60^{\circ}$ and $180^{\circ}$ cross sections are similar at shown in Table 4 .

Table 4: Separation comparison for the $O$-ring assembly at the $60^{\circ}$ and $180^{\circ}$ cross sections, at the O-ring groove at $0.028,0.032$, and $0.035 \mathrm{~ms}$.

\begin{tabular}{|c|c|c|c|}
\hline \multirow{2}{*}{$\begin{array}{c}\text { Cross section separation } \\
\text { at O-ring groove (in.) }\end{array}$} & \multicolumn{3}{|c|}{ Time after impact (ms) } \\
\cline { 2 - 4 } & 0.028 & 0.032 & 0.035 \\
\hline $60^{\circ}$ & 0.036 & 0.041 & 0.040 \\
\hline $180^{\circ}$ & 0.030 & 0.040 & 0.040 \\
\hline
\end{tabular}

Adding a separation of $0.041 \mathrm{in}$. to the nominal groove depth of 0.152 in., the gap in the $\mathrm{O}$-ring assembly is $0.193 \mathrm{in}$. The compression on the O-ring with nominal diameter of $0.21 \mathrm{in}$. is $9.25 \mathrm{lb} / \mathrm{in}$. The capsule impact reduced the compression on the O-ring from 50 $\mathrm{lb} /$ in to $9.25 \mathrm{lb} / \mathrm{in}$. Considering the tolerances in the groove and O-ring, the compression on the O-ring is reduced from $50 \mathrm{lb} /$ in to $1.3 \mathrm{lb} / \mathrm{in}$. When the projected separation of 0.044 in. from the $80^{\circ}$ drop is considered, the compression is slightly less than that from the $70^{\circ}$ drop.

Although the juice can does not provide material containment, for completeness of the evaluation, the maximum effective stresses at two locations were investigated, at the impact point (Elements $900,904,929$, and 933) and at the center of the top plate (Elements 900,661,963,966,973, and 974). These two groups of the shell elements are highlighted in Fig. 8.10. The maximum effective stress time histories are shown in Fig. 8.11, while the effective plastic strain time histories are shown in Fig. 8.12.

The shell elements at the center of the top plate experience low stresses and plastic strains. On the other hand, Elements 973 and 974 , which are at the impact point, suffer high stresses and'high plastic strains. Although the plastic strain in the adjacent shell elements (963 and 966 inside the cylinder) are moderately low, the assumption could be made that the crimped joint might also be damaged.

\subsection{Summary of structural evaluation}

Two computer models were generated to simulate a credible accident for the storage container. Model 1 simulated the maximum mass at the point of contact, while Model 2 simulated the dynamic impact from the travelling capsule and juice can. The calculations were terminated after the separations in the lid and flange were converged.

Model 1 was tested at four angles of contact: $20^{\circ}, 30^{\circ}, 37^{\circ}$ and $51.76^{\circ}$ with respect to the 
longitudinal axis. The maximum separation at the O-ring assembly occurred at the $37^{\circ}$ drop and reduced the compression on the O-ring it a range of $60 \%$ to $20 \%$. The low comfort margin led to the investigation of the impact from the travelling capsule and juice can.

The Model 2, which included the capsule was tested at five angles of contact: $37^{\circ}, 51.76^{\circ}$, $62.64^{\circ}, 70^{\circ}$ and $90^{\circ}$. The projected worst case was a $80^{\circ}$ drop. The separation at the O-ring assembly estimated in the $70^{\circ}$ drop was $0.041 \mathrm{in}$. which reduced the compression on the $\mathrm{O}$-ring to a range of $18 \%$ to $3 \%$. The remaining $\mathrm{O}$-ring compression in a damaged storage container would be too low to maintain material containment. The flexible juice can, being compressed between the capsule and container, would be damaged also and not able to provide material containment.

\subsection{Conclusion and Recommendations}

In conclusion, the analysis revealed that in the very unlikely event of a container drop from the top shelf, the integrity of the hermetic seal of the storage container could be compromised due to plastic deformation of the lid and mating flange. It is recommended that simple engineering and administrative controls be implemented to preclude such an occurrence. These could include inserting a spacer to decrease the gap between the uppermost shelf and the shield plug or extending the height of the lip on the shelf to prevent a container from tumbling off.

For new design of container in the future, a thicker lid or adding more bolts to the lid would reduce the deflection. Model 2 may be revised to represent a new thick lid and more fastening bolts for confirmation. 


\subsection{References}

Ref. 1. U.S. Department of Energy Order 5480.23 (4-30-92), “Nuclear Safety Analysis Reports," U.S. Department of Energy, Washington, DC., 1992.

Ref. 2. Lawrence Livermore National Laboratory, "Safety analysis Report for the Heavy Element Facility (Building 251)," UCRL-AR-113377, Rev. 2, June 24, 1996.

Ref. 3. O. Connell, W.J., "Hazard Analysis for B-251 Underground Storage Vaults," Lawrence Livermore National Laboratory, July 30, 1997.

Ref. 4. U.S. Department of Energy Standard 1027-92, "Hazard Categorization and Accident Analysis Technique for Compliance with DOE Order 5480.23, Nuclear Safety Analysis Reports," U.S. Department of Energy, Washington, DC. 1992.

Ref. 5. 10CFR71, "Code of Federal regulation," Chapter 10, Energy, Part 71, Packaging and Transportation of Radioactive Material, pp. 204-239, The Office of the Federal Register National Archives and Records Administration, January 1995.

Ref. 6. Lin, J.I., "A Nonlinear, Explicit, Three-Dimensional Finite Element Code For Solid and Structural Mechanics - User Manual," Lawrence Livermore National Laboratory, UCRL-MA-107254, November 1997.

Ref. 7. XYZ Scientific Applications, Inc., "TrueGrid Manual," Version 0.99, XYZ Scientific Applications, Inc., October 1995.

Ref. 8. Parker Seals Group O-ring Division, "Parker O-ring Handbook," Parker Hannifin Corporation, Cleveland, OH, ORD 5700, 1992. 
Figure 1.1. The underground storage rack (not to scale)

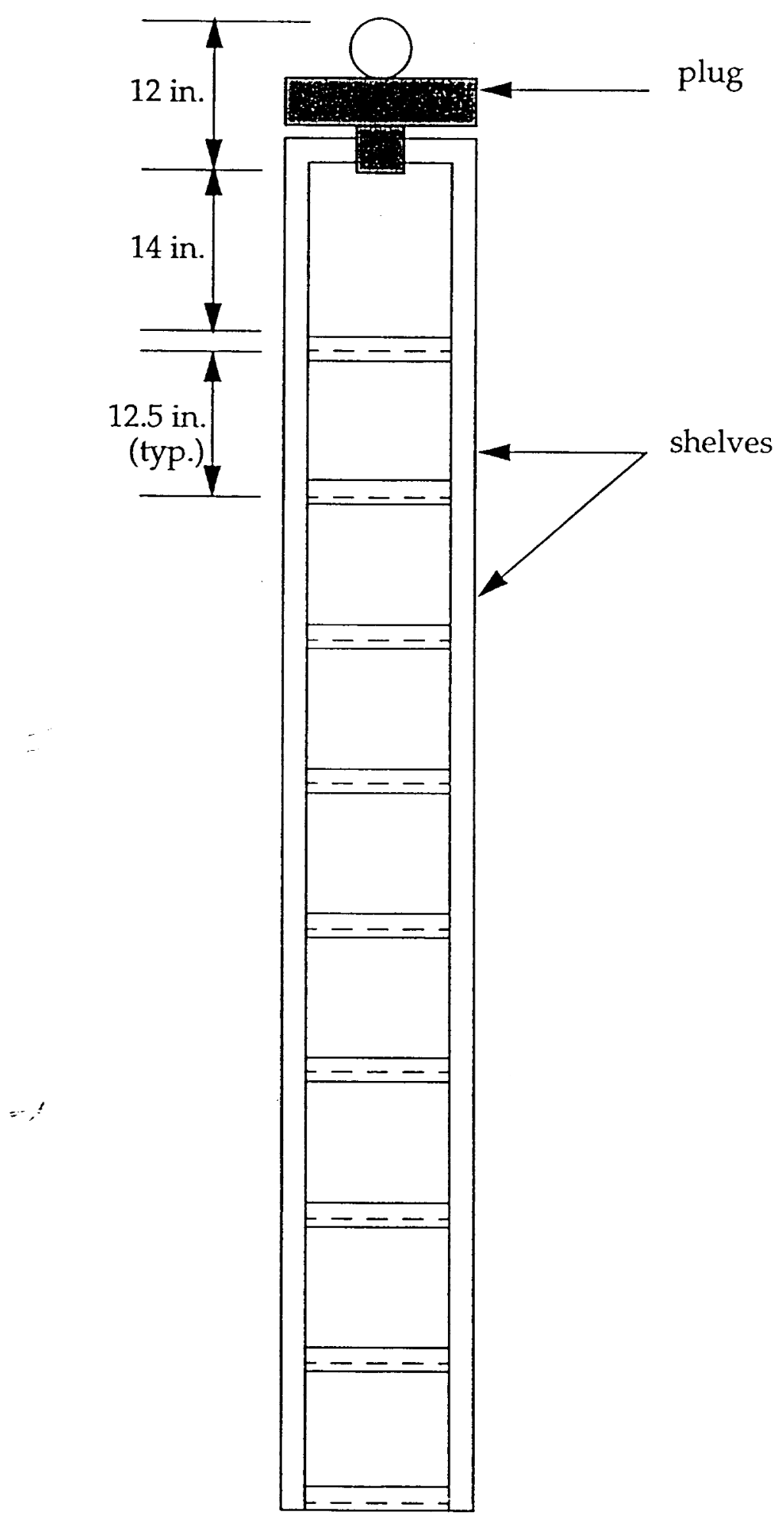


Figure 3.1. A detailed drawing of the storage container.

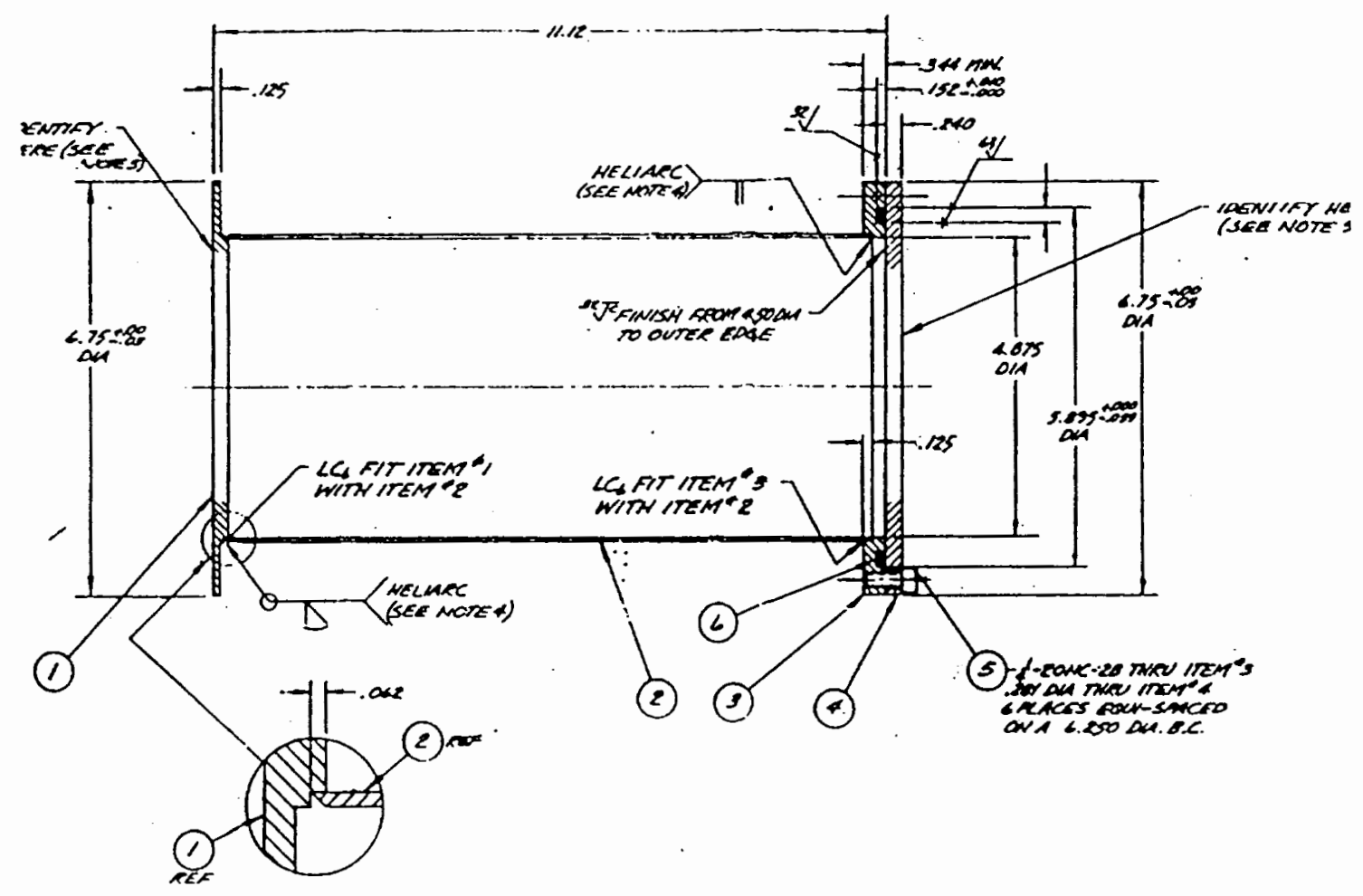


Figure 5.1. Model 1 is configured for maximum mass impact on the flanges.

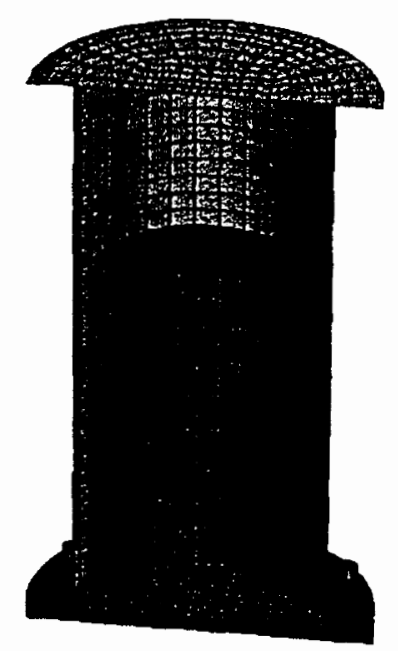

Model 1: Container and juice can

Figure 5.2. Model 2 is configured to capture the impact from the capsule and juice can travelling inside the container.

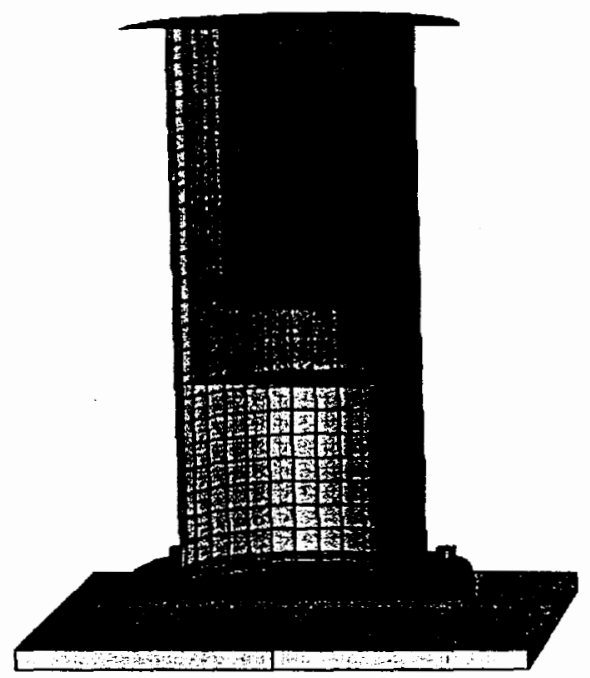

Model 2: Container, juice can, and capsule

(c) 
Figure 5.3. A close-up view of the deformed O-ring assembly after a $51.76^{\circ}$ drop.

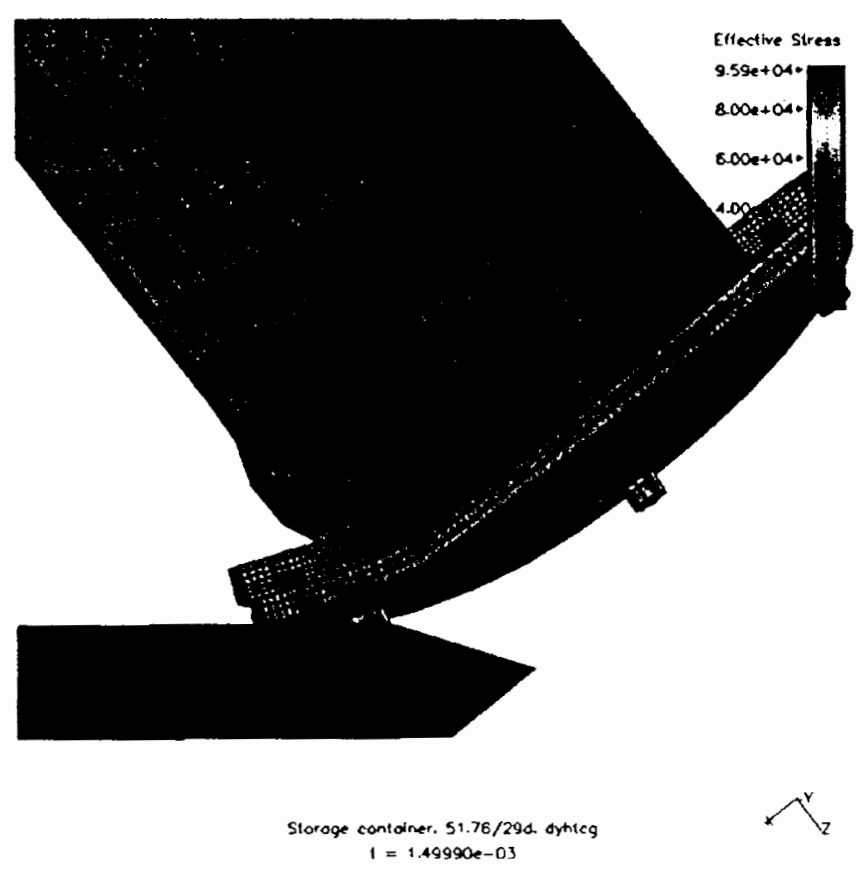

Figure 5.4. A close-up view of the lid/flange separation after a $51.76^{\circ}$ drop.

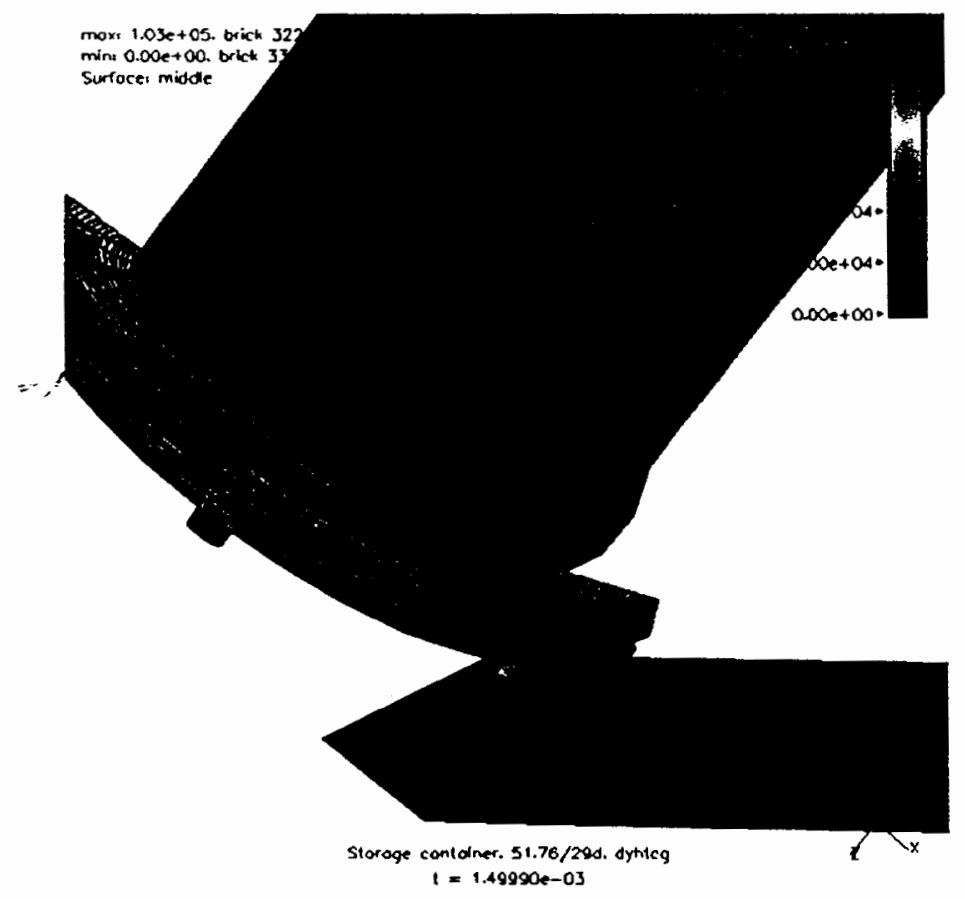


Figure 7.1. A composite plot of the deformed models and effective stress distribution of three drop orientations: (a) $20^{\circ}$, (b) $30^{\circ}$, and (c) $51.76^{\circ}$.

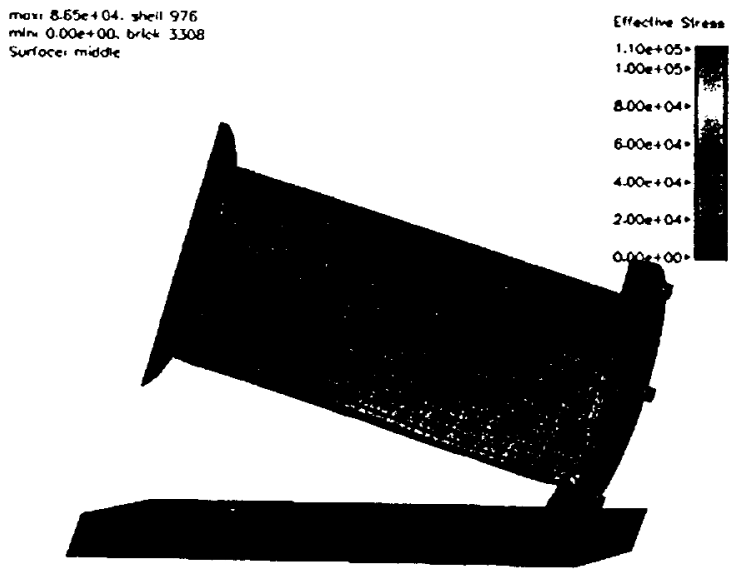

(a)

Stge con 4 try ent. aytizoi. 2 $1=1.49990 e-03$

$$
\hat{L}^{r}
$$

(b)

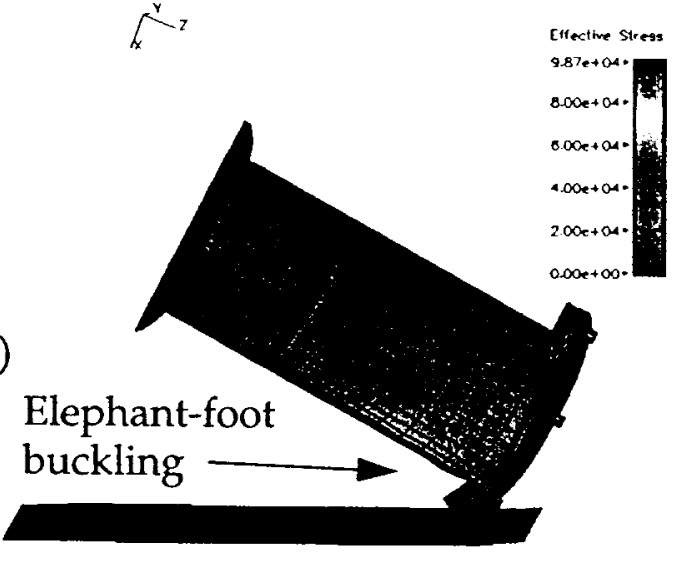

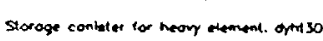

(c)

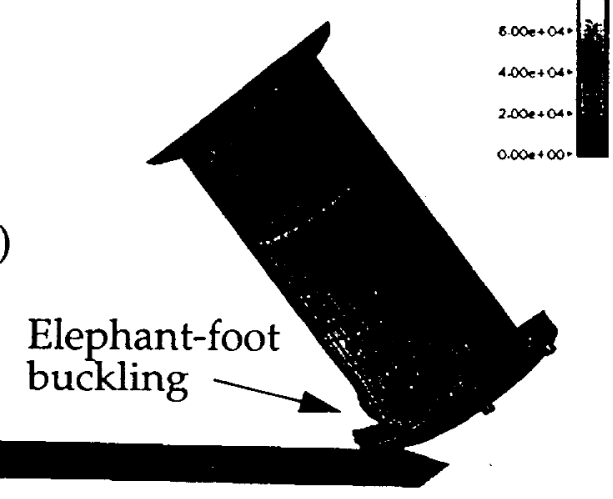


Figure 7.2. A composite plot of the effective stress time histories of three drop orientations: (a) $20^{\circ}$, (b) $30^{\circ}$, and (c) $51.76^{\circ}$.
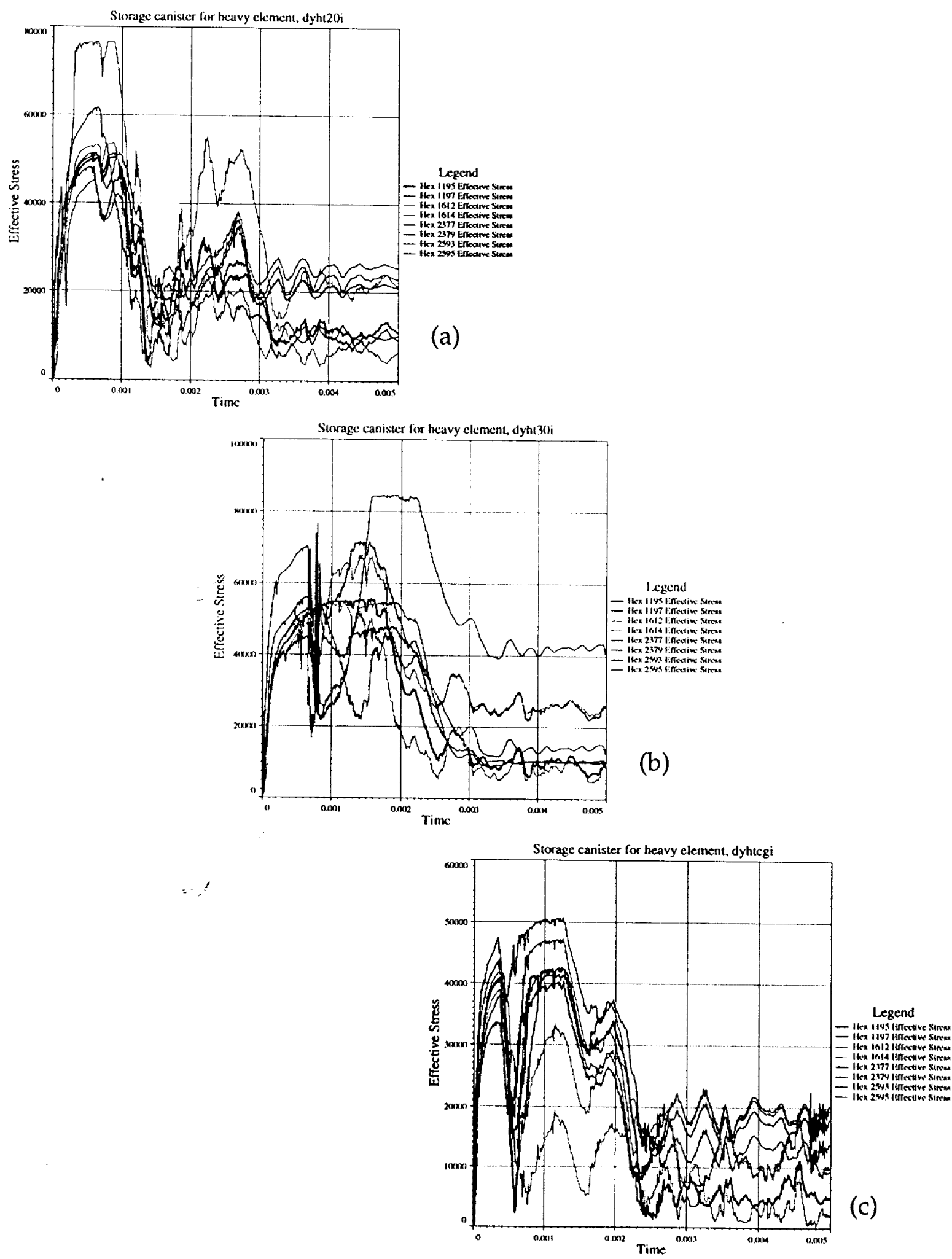
Figure 7.3. A composite plot of the longitudinal displacement time histories of three drop orientations: (a) $20^{\circ}$, (b) $30^{\circ}$, and (c) $51.76^{\circ}$.
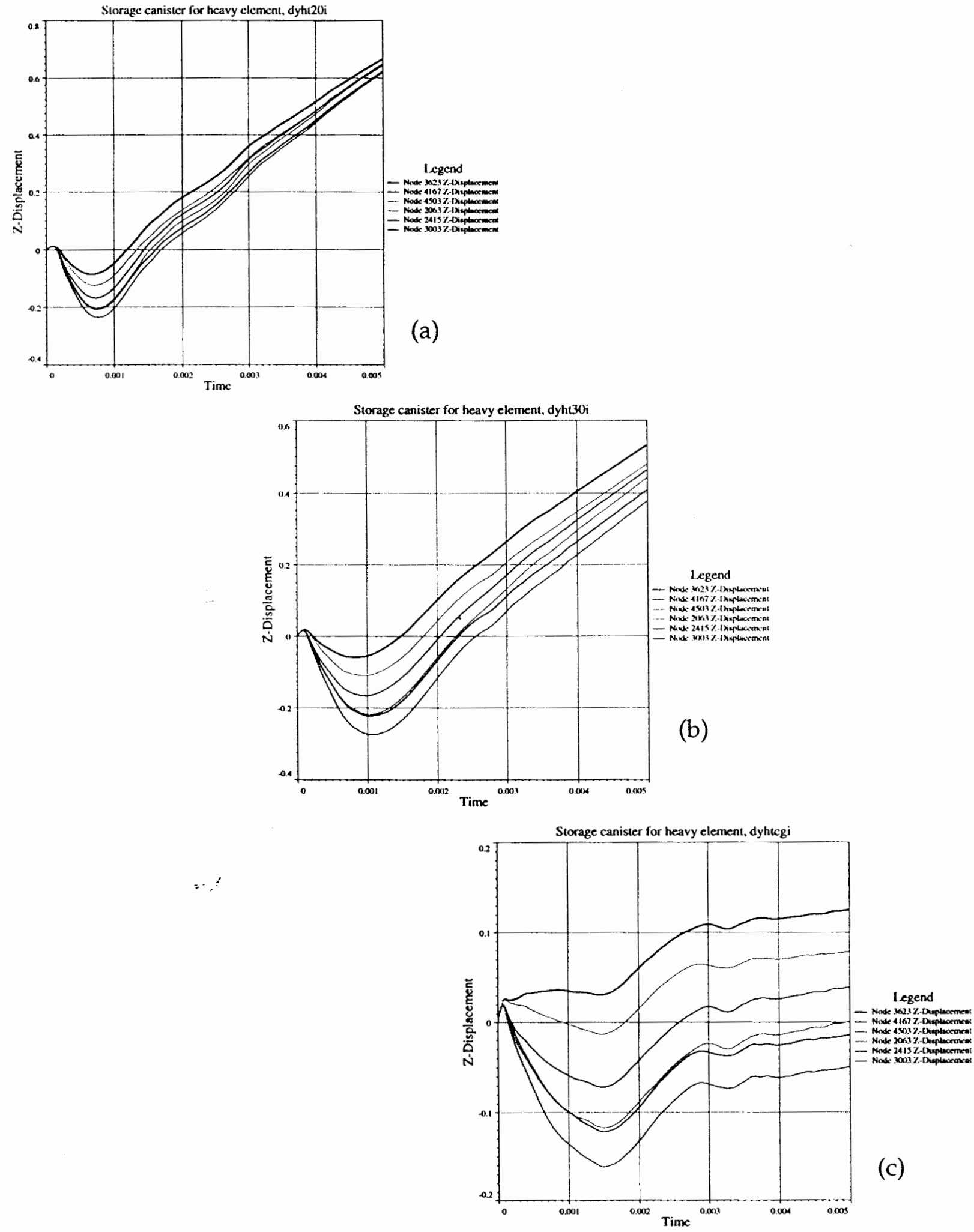
Figure 7.4. The projected drop angle for maximum deformation.

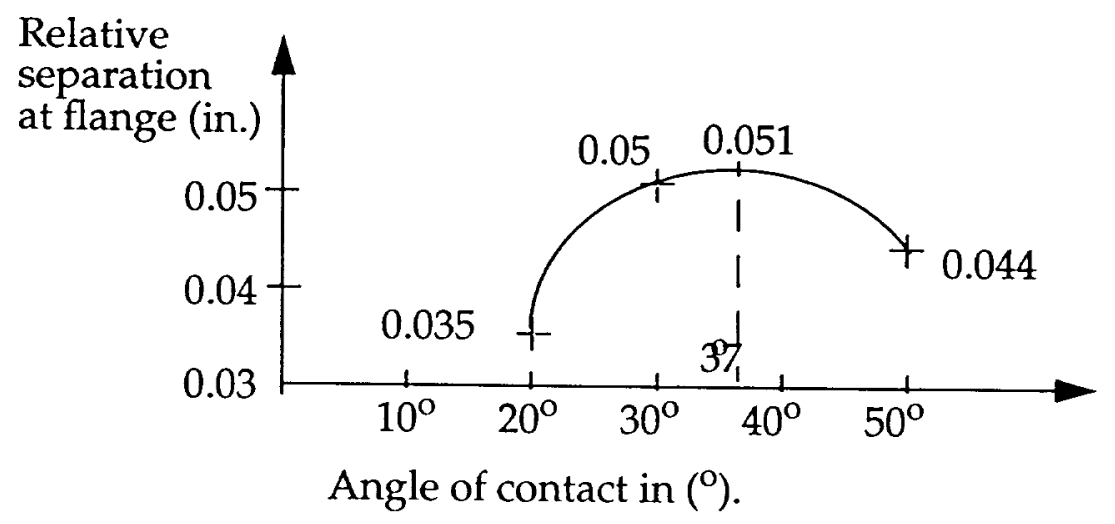


Figure 7.5. A close-up view of the deformed O-ring assembly after the $37^{\circ}, 17.5 \mathrm{ft}$ drop.

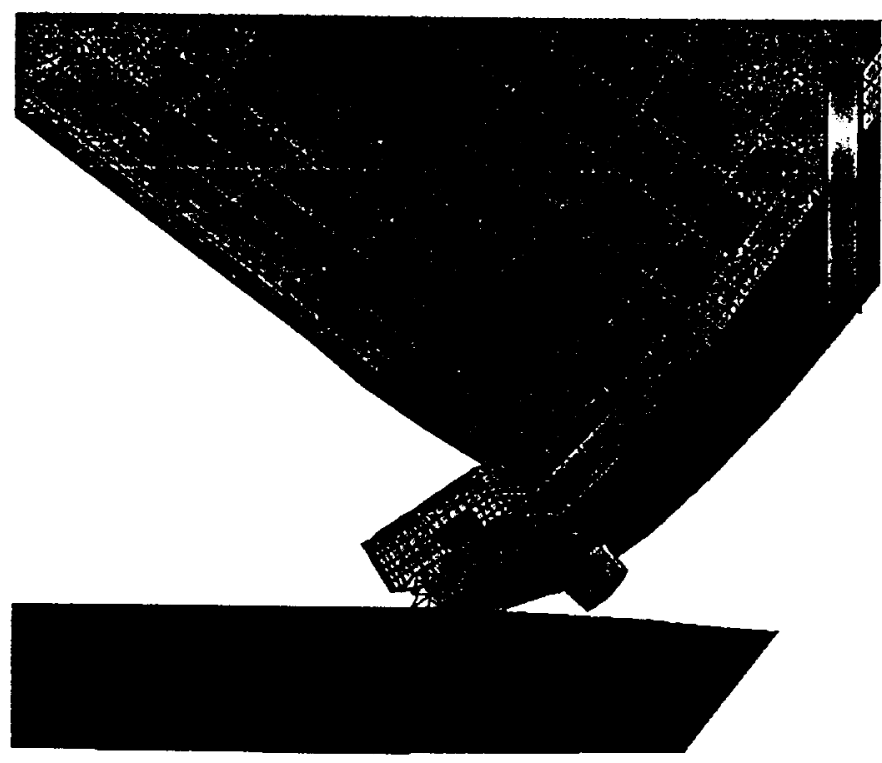

Storoge contoinre for heovy element. 17.5ft. 37d drop. dyth17l

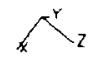

$t=1.49994 e-03$

Figure 7.6. a closed-up view of the lid/flange separation after the $37^{\circ}, 17.5 \mathrm{ft}$ drop.

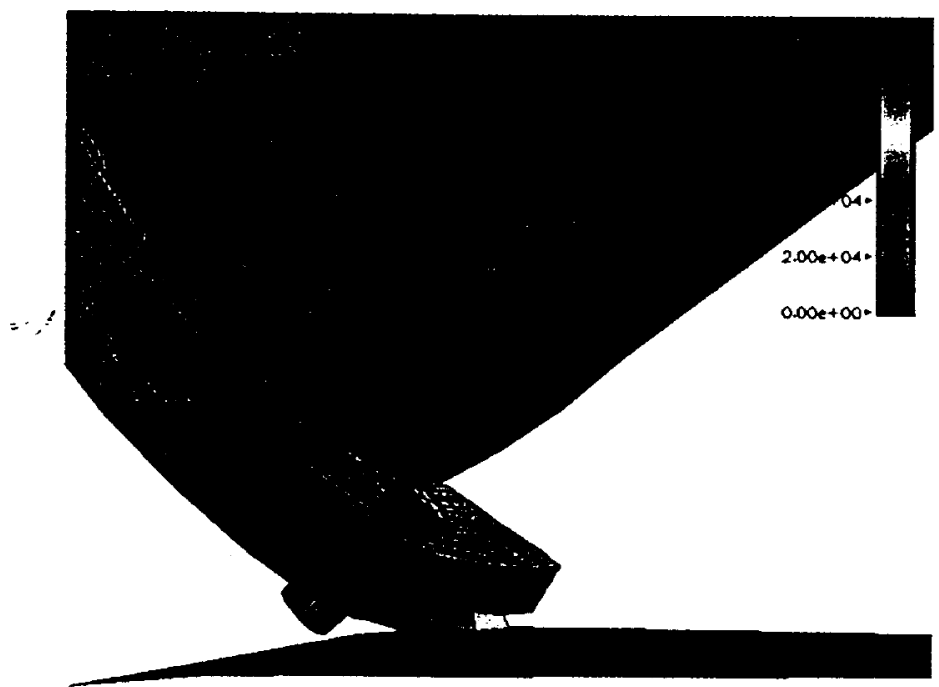

Storoge contoince for neovy element. 17.5nt. 37d drop. dyti17t $t=1.74999+-03$ 
Figure 7.7. The longitudinal displacement time histories along the symmetry plane from the $37^{\circ}, 17.5 \mathrm{ft}$ drop at (a) flange, (b) bolt hole, and (c) groove.
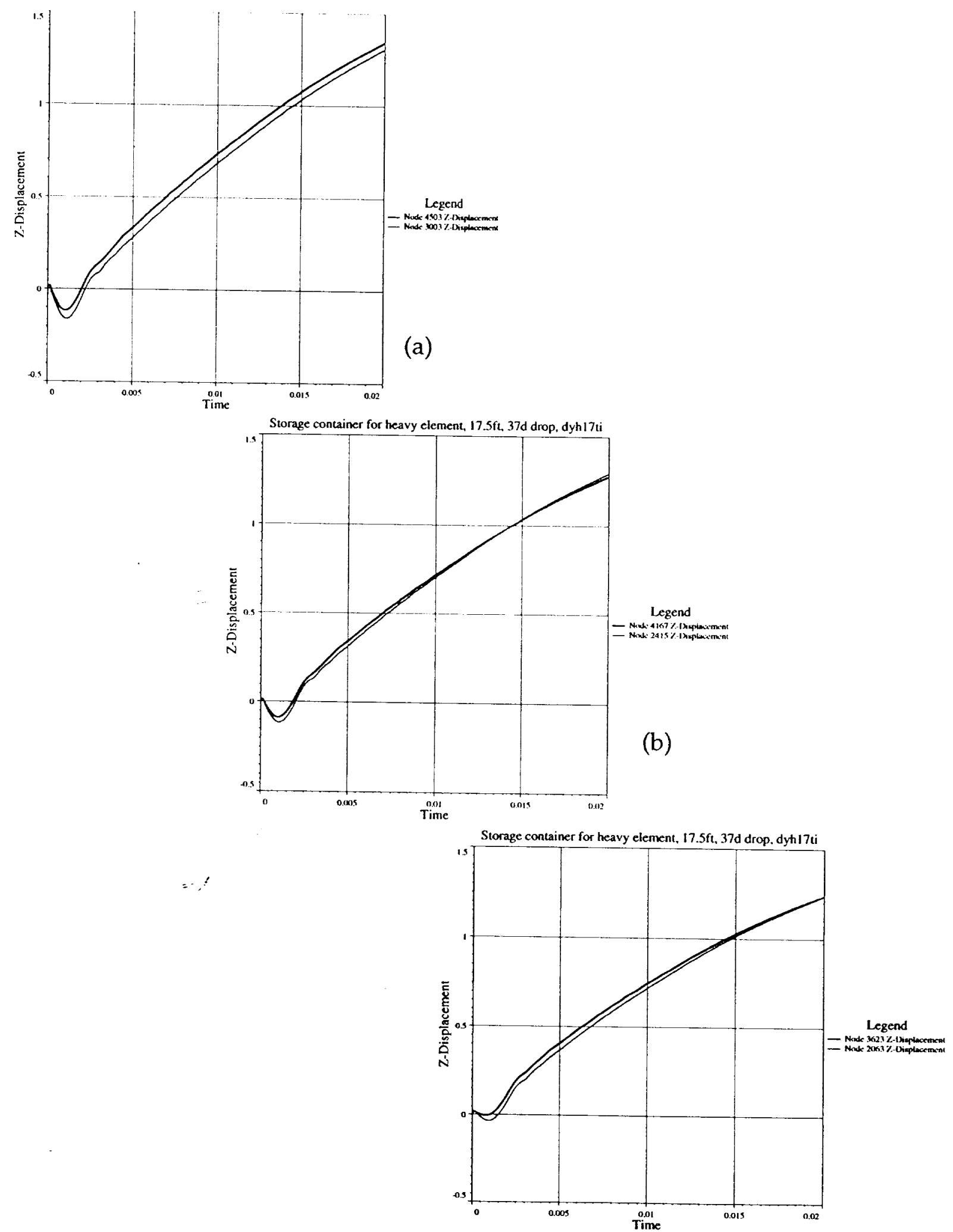
Figure 7.8. The longitudinal displacement time histories along the symmetry plane from the $37^{\circ}, 17.5 \mathrm{ft}$ drop at (a) flange, (b) bolt hole, and (c) groove.

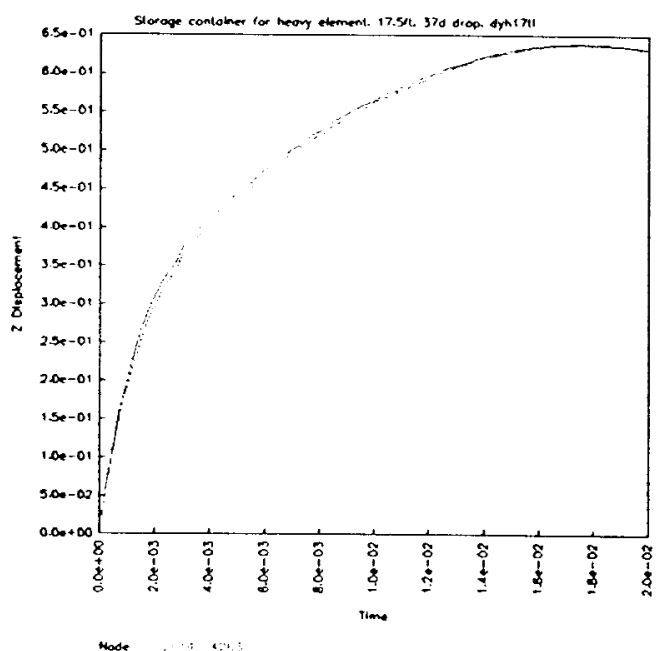

(a)

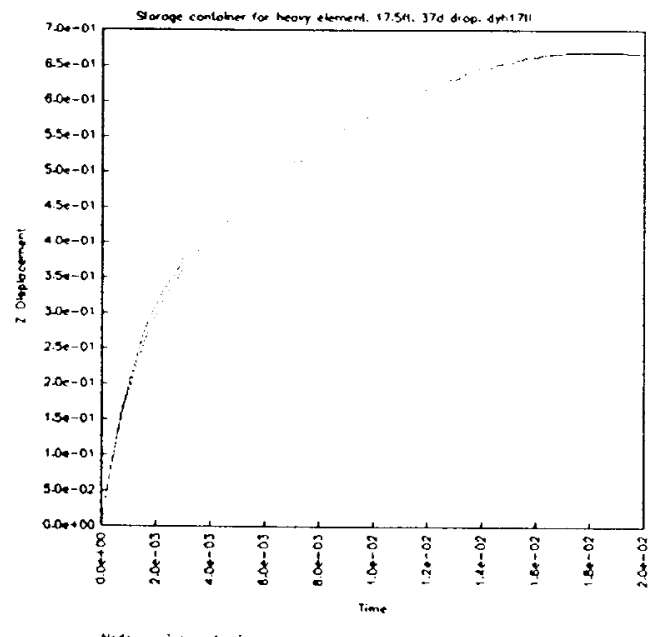

(b)

(c)

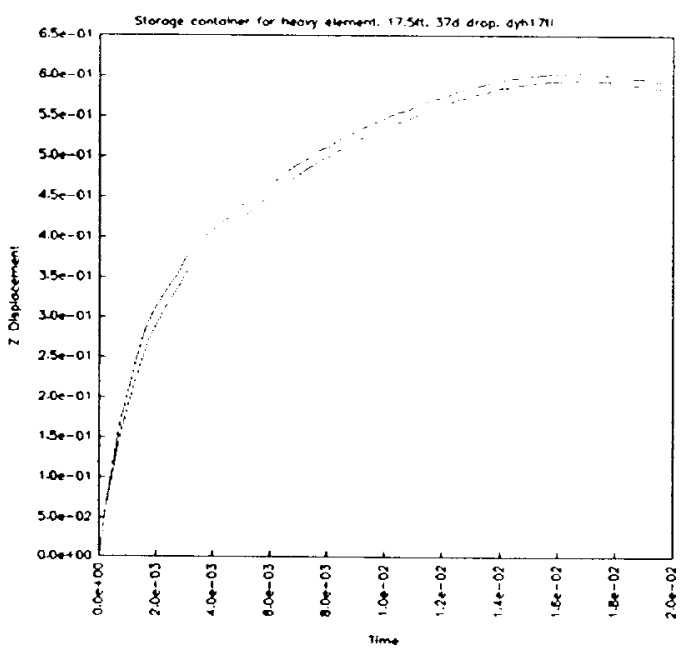


Figure 7.9. A schematic of the deformed O-ring assembly

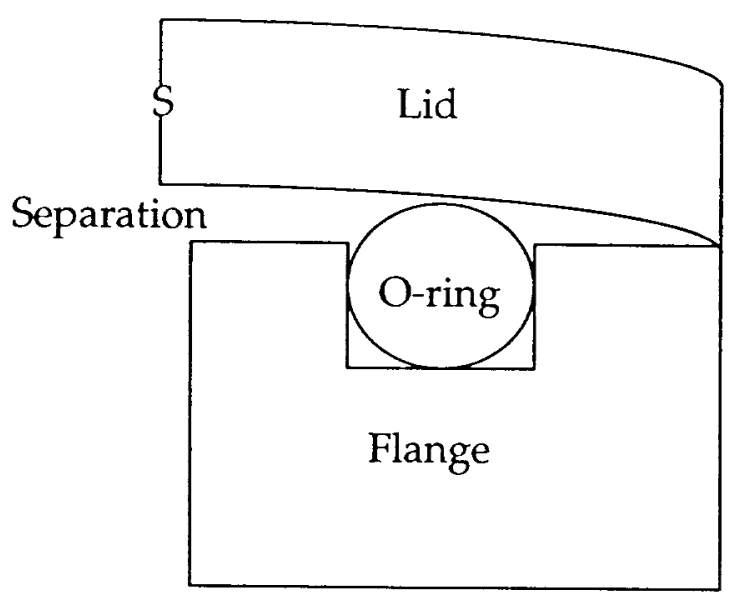

Figure 8.1. The deformed shape and position of Model 2 at $27 \mathrm{~ms}$ after impact at the $37^{\circ}$ orientation and $17.5 \mathrm{ft}$ drop.

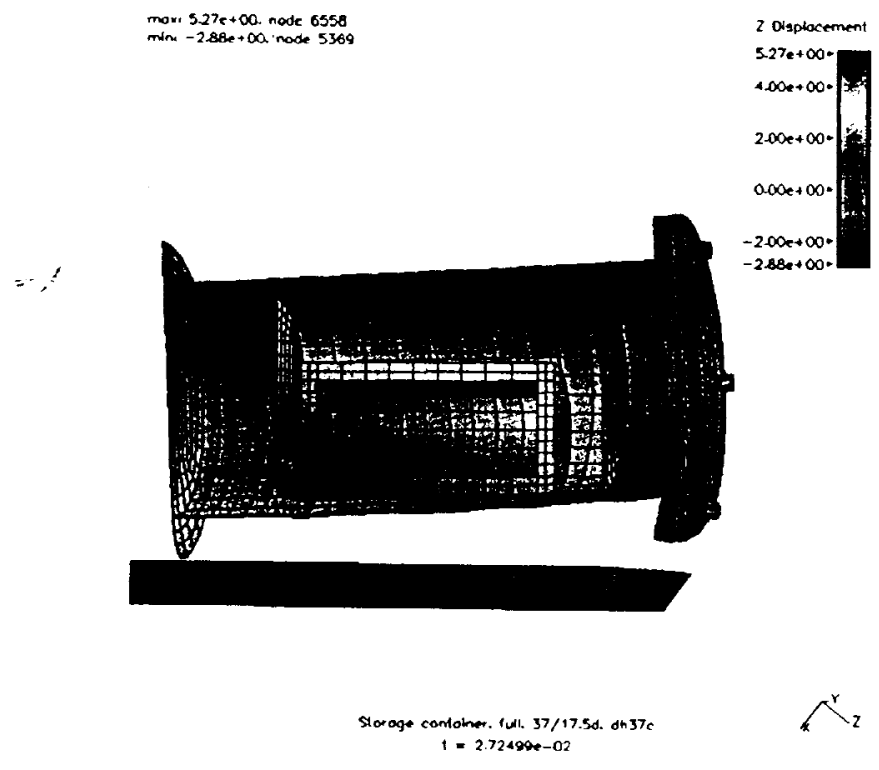


Figure 8.2. A composite plot of the deformed model and longitudinal displacement distribution of: (a) $62.64^{\circ}$, (b) $70^{\circ}$, and (c) $90^{\circ}$.

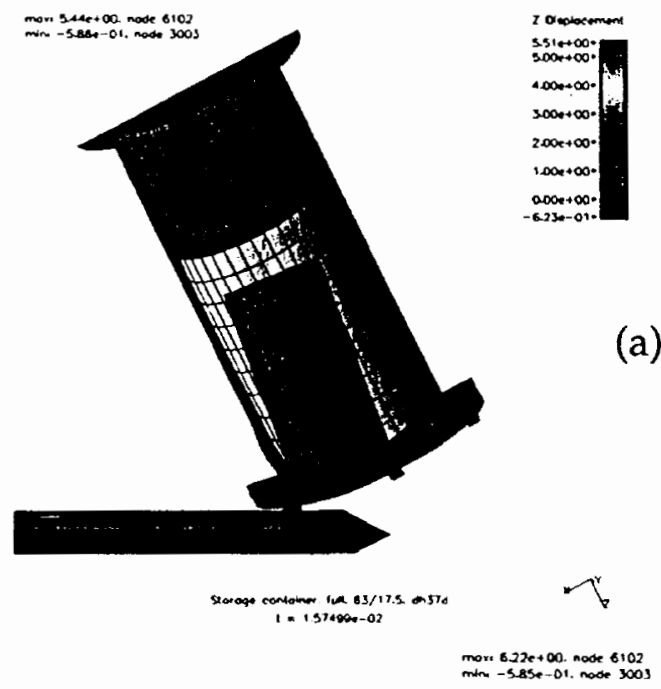

(a)

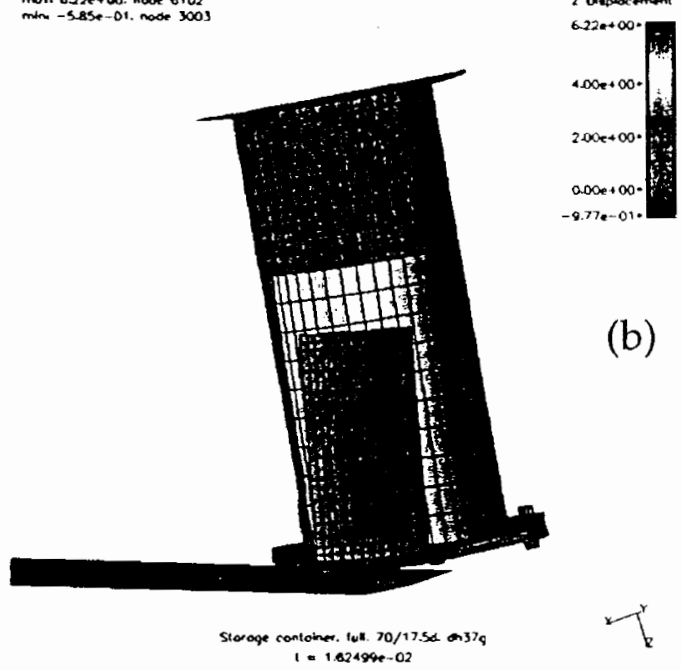

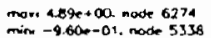

(c)
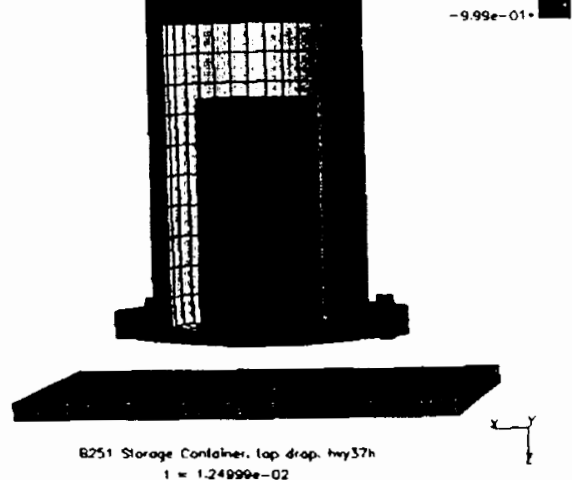
Figure 8.3. A composite plot of the effective stress time histories of three drop orientations: (a) $62.64^{\circ}$, (b) $70^{\circ}$, and (c) $90^{\circ}$.
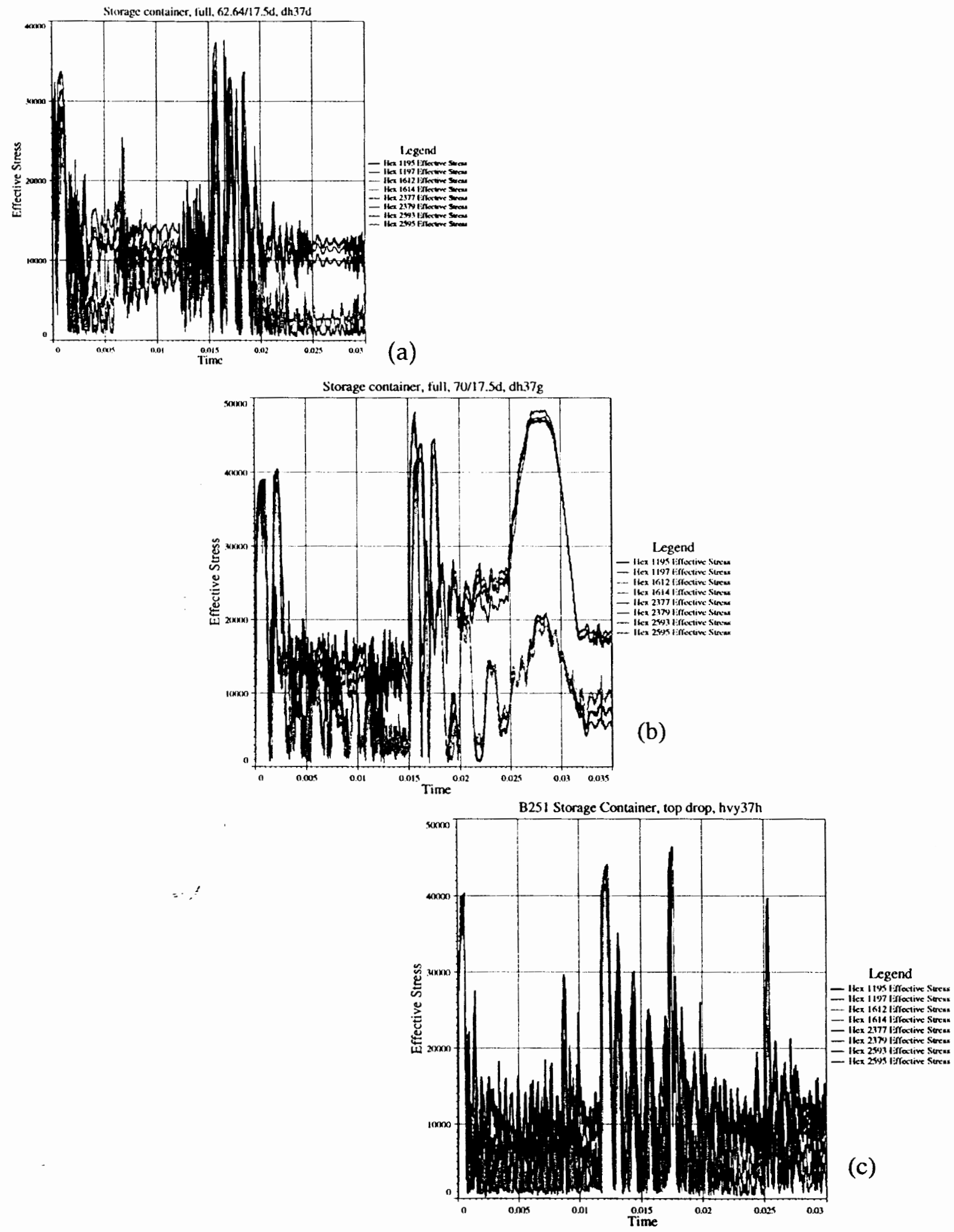
Figure 8.4. A composite plot of the longitudinal displacement time histories of three drop orientations: (a) $62.64^{\circ}$, (b) $70^{\circ}$, and (c) $90^{\circ}$.
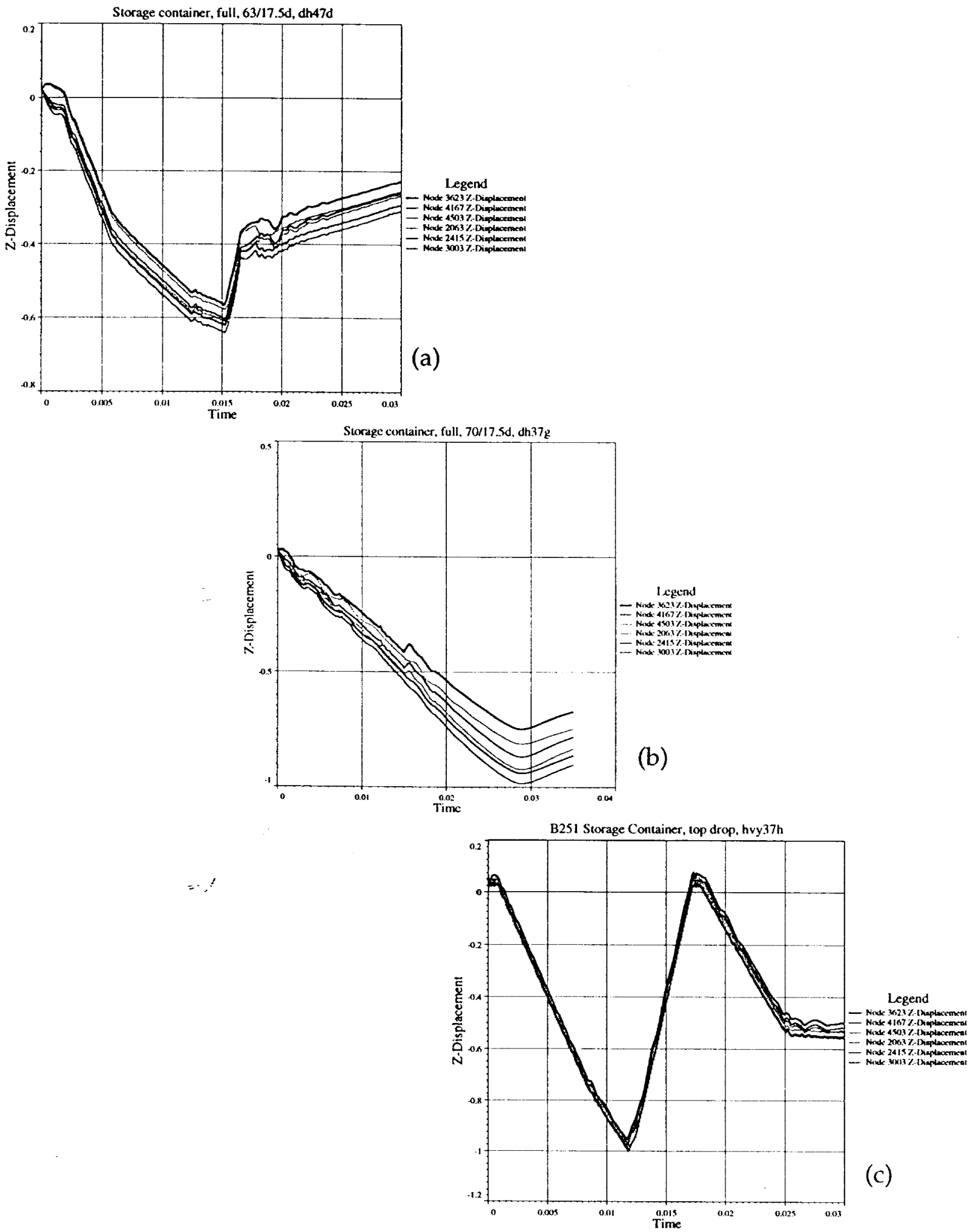
Figure 8.5. The projected drop angle for maximum deformation.

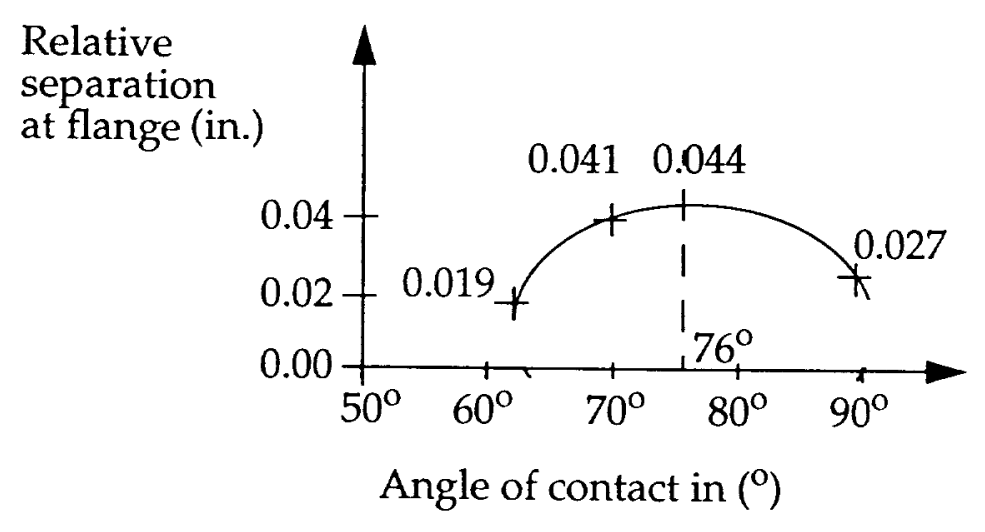


Figure 8.6. A close-up view of the deformed O-ring assembly after the $70^{\circ}, 17.5 \mathrm{ft}$ drop.

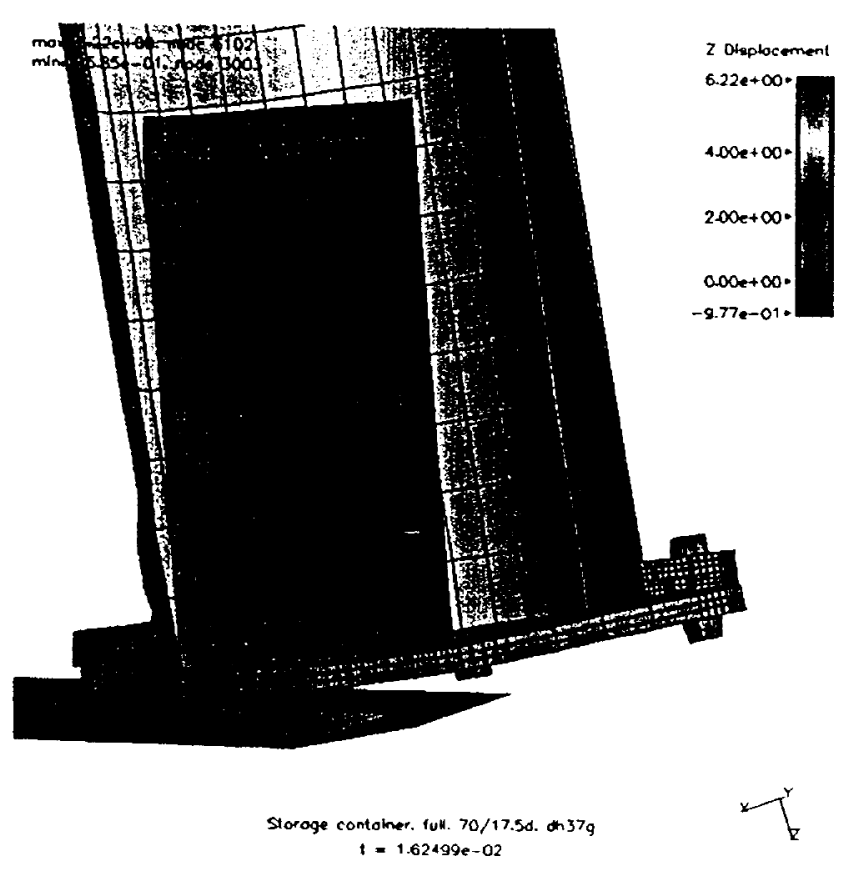

Figure 8.7. A close-up view of the lid/flange separation after the $70^{\circ}, 17.5 \mathrm{ft} \mathrm{drop}$. 
Figure 8.8. The longitudinal displacement time histories on the symmetry plane from the $70^{\circ}, 17.5 \mathrm{ft}$ drop at (a) flange, (b) bolt hole, and (c) groove.
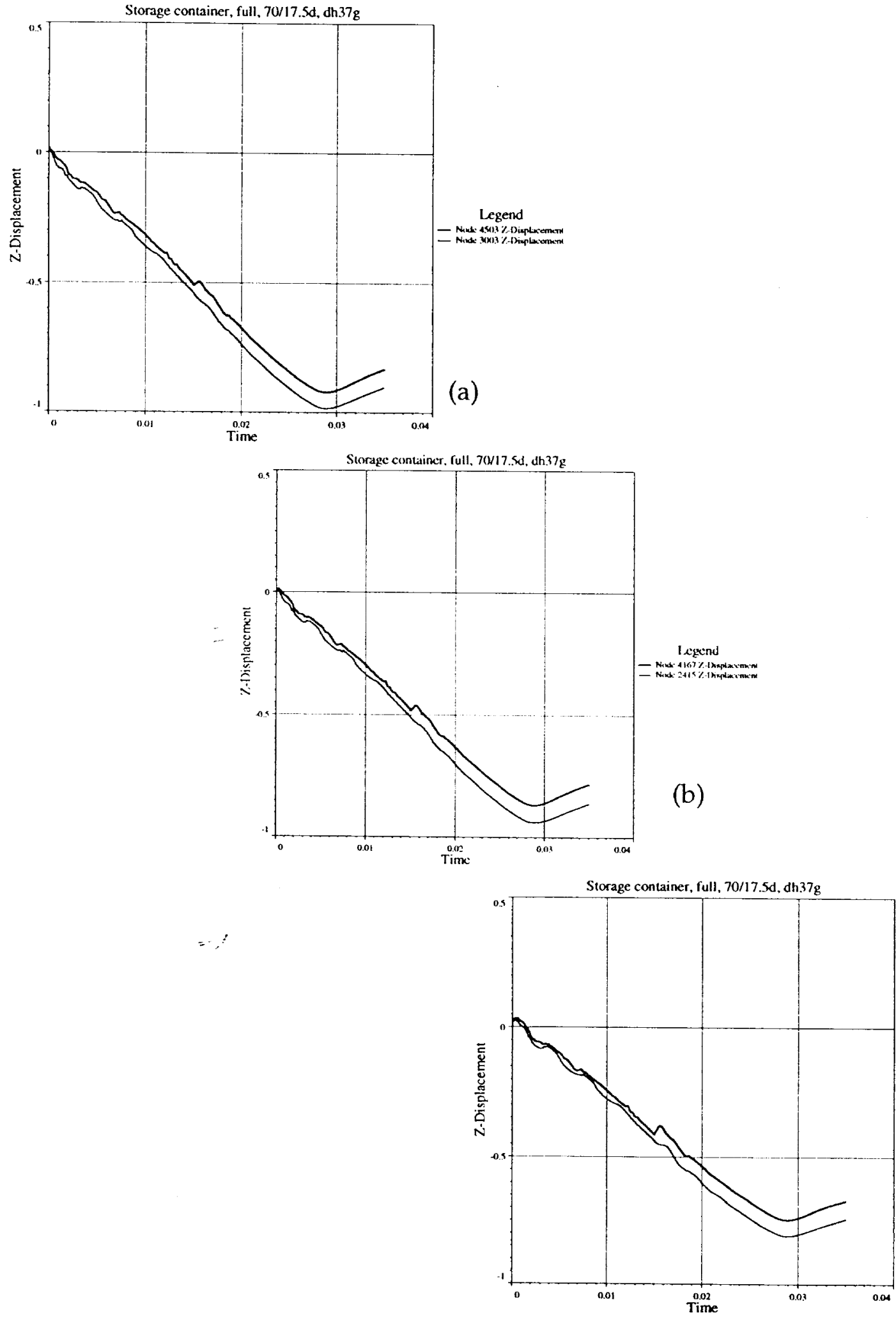

(c) 


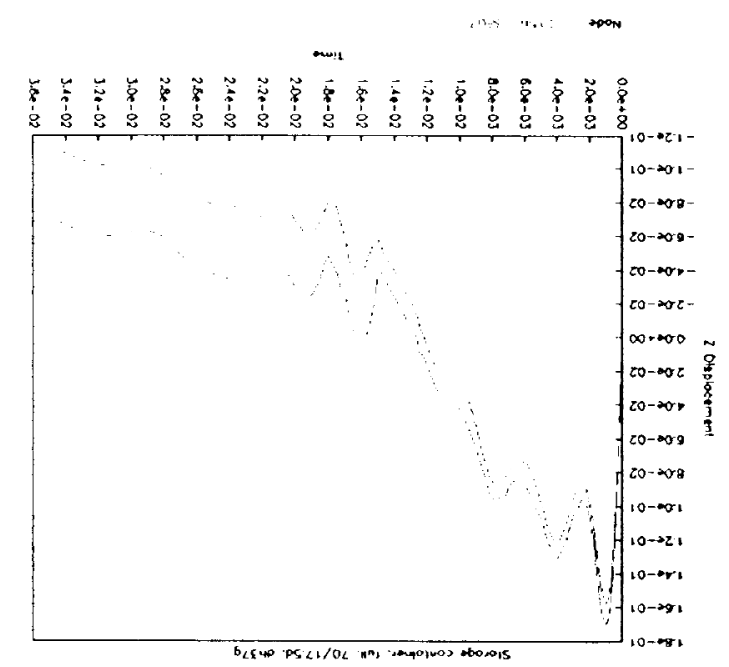

(ग)

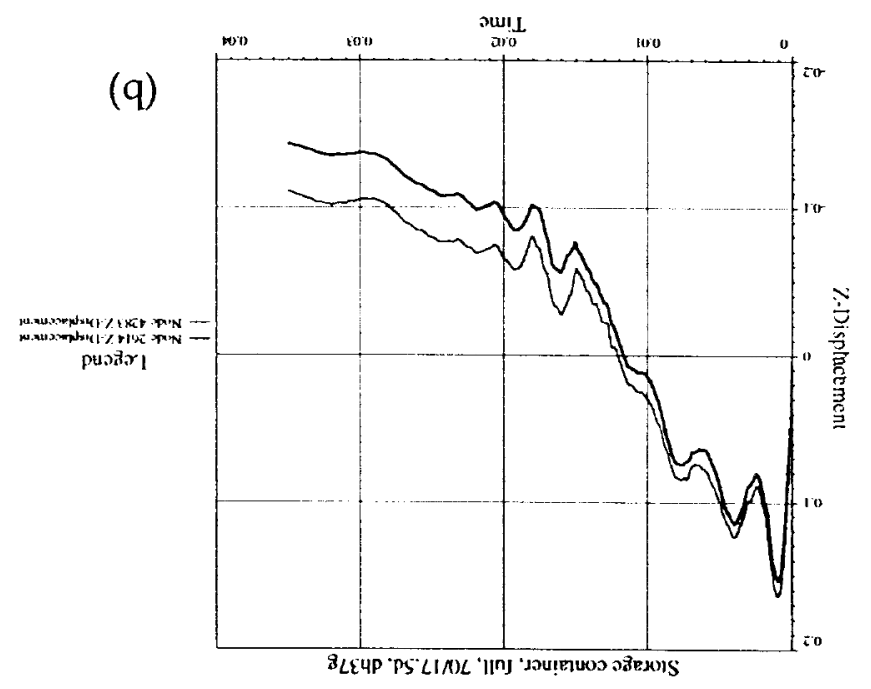

(e)

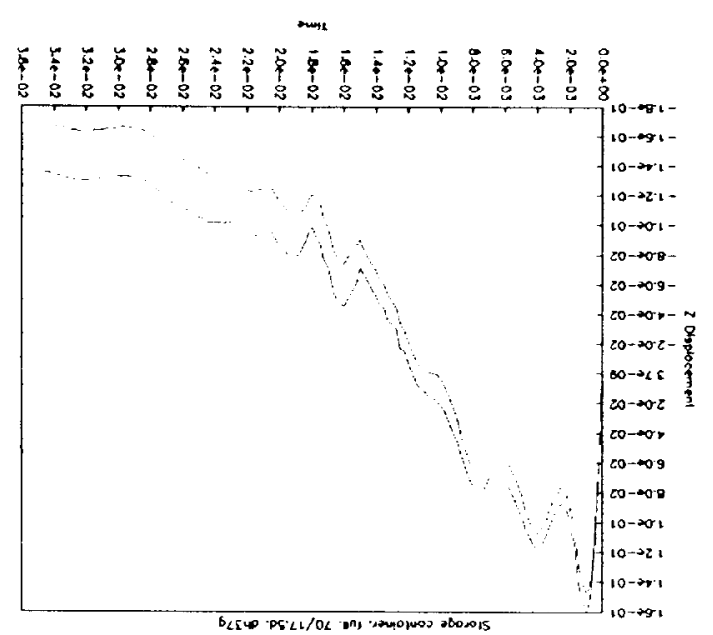

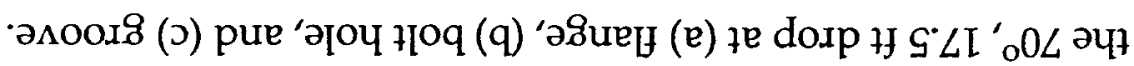

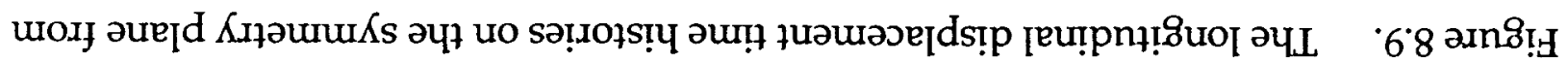


Figure 8.10. Two groups of shell elements in the juice can were evaluated.

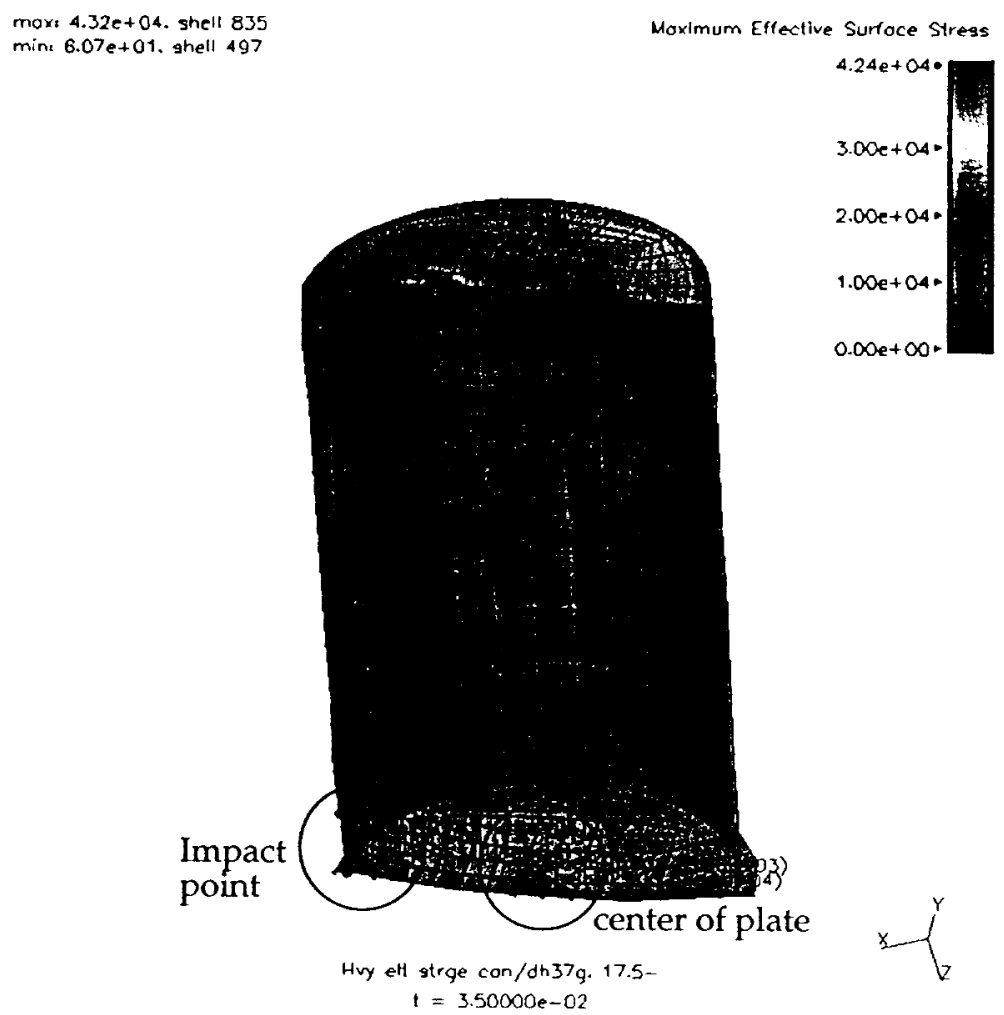

Figure 8.11. The maximum effective stress time histories in the juice can.

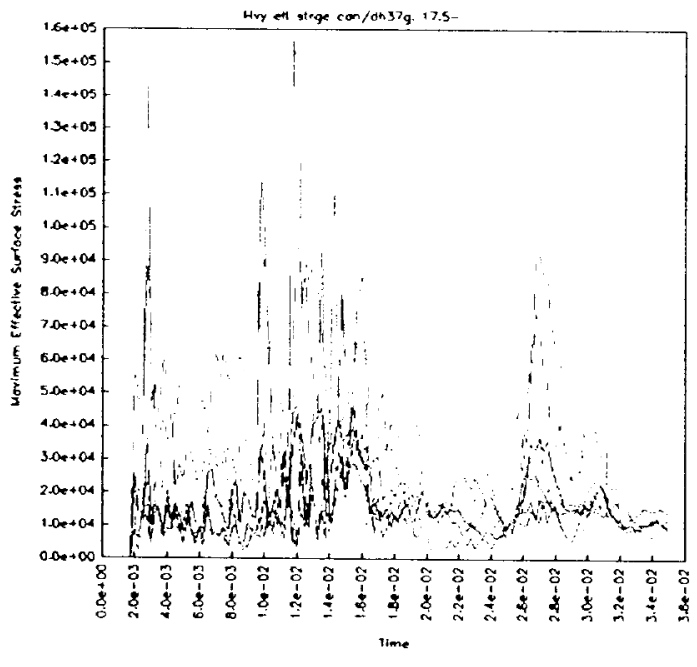


Figure 8.12. The effective plastic strain time histories in the juice can.

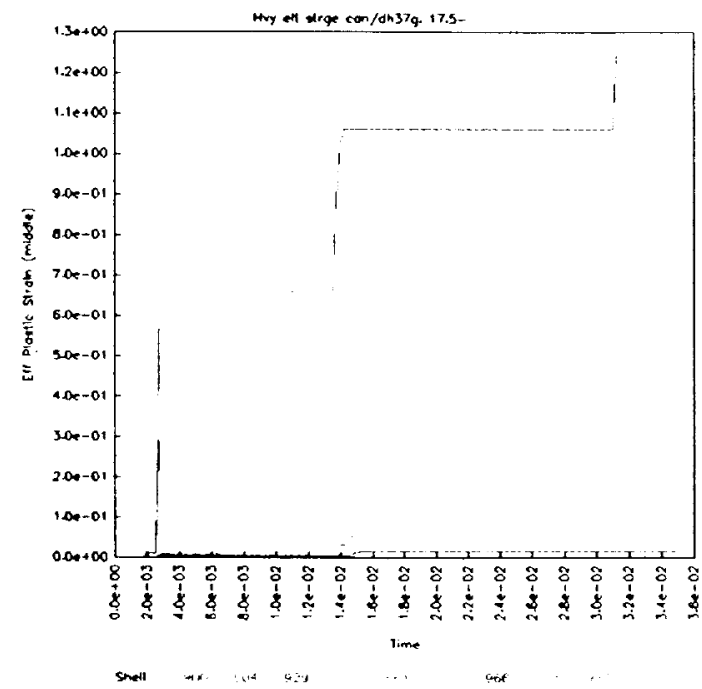

